\title{
La especialización del trabajo: teoría y arqueología. El caso de los orfebres Mochicas
}

La spécialisation du travail: théorie et archéologie. Le cas des orfêvres mochicas The craftsman specialization: theory and archaeology. The case of Mochicas metalsmith

\section{Santiago Uceda Castillo y Carlos E. Rengifo Chunga}

\section{OpenEdition}

Journals

\section{Edición electrónica}

URL: http://journals.openedition.org/bifea/4574

DOI: $10.4000 /$ bifea. 4574

ISSN: 2076-5827

\section{Editor}

Institut Français d'Études Andines

\section{Edición impresa}

Fecha de publicación: 1 mayo 2006

Paginación: 149-185

ISSN: 0303-7495

\section{Referencia electrónica}

Santiago Uceda Castillo y Carlos E. Rengifo Chunga, «La especialización del trabajo: teoría y arqueología. El caso de los orfebres Mochicas », Bulletin de l'Institut français d'études andines [En línea], 35 (2) | 2006, Publicado el 08 mayo 2006, consultado el 01 diciembre 2020. URL : http:// journals.openedition.org/bifea/4574; DOl : https://doi.org/10.4000/bifea.4574

\section{(c) (†) $\ominus$}

Les contenus du Bulletin de l'Institut français d'études andines sont mis à disposition selon les termes de la licence Creative Commons Attribution - Pas d'Utilisation Commerciale - Pas de Modification 4.0 International. 


\title{
La especialización del trabajo: teoría y arqueología. El caso de los orfebres Mochicas
}

\author{
Santiago Uceda Castillo* \\ Carlos E. Rengifo Chunga**
}

\begin{abstract}
Resumen
La especialización artesanal en las sociedades prehispánicas es un tema que últimamente ha venido despertando el interés de los investigadores, dado que se empieza a reconocer la activa y directa participación de los artesanos en la construcción de las relaciones de poder, prestigio y status en las sociedades complejas.

En esta ocasión presentamos el caso de los artesanos orfebres de la sociedad Mochica, a partir de los datos provenientes del sitio Huacas de Moche. La información obtenida de este sitio y su comparación, tanto con sitios contemporáneos como con información asociada a otros periodos de la prehistoria peruana, nos permiten abordar el tema desde las perspectivas de evolución tecnológica, características constructivas de las áreas de producción metalúrgica y de las relaciones sociales generadas a partir de los condicionantes políticos e ideológicos que rodeaban las actividades de producción de objetos metálicos.
\end{abstract}

Palabras clave: cultura Moche (Mochica), huacas del Sol y de la Luna (Huacas de Moche), teoría arqueológica, especialistas, artesanos, orfebres

\section{La spécialisation du travail: théorie et archéologie. Le cas des orfèvres mochicas}

\section{Résumé}

La spécialisation artisanale dans les sociétés préhispaniques, est un sujet qui a attiré dernièrement I'intérêt des chercheurs. La participation active des artisans dans la construction des relations de pouvoir, prestige et de statut dans les sociétés complexes commence à être acceptée.

Dans cet article, nous présentons le cas des artisans orfèvres de la société Mochica, à partir de données provenant du site Huacas de Moche. L'information obtenue de ce site et la comparaison avec les sites contemporains mochica et d'autres périodes de la préhistoire péruvienne nous permettent d'aborder

* Santiago Uceda Castillo, Universidad Nacional de Trujillo. E-mail: uceda@speedy.com.pe

** Carlos Rengifo Chunga, Pontificia Universidad Católica del Perú. E-mail: crengifo@pucp.edu.pe 
ce sujet à partir des perspectives de l'évolution technologique, des caractéristiques constructives des aires de production métallurgiques et des relations sociales générées par des conditionnements politiques et idéologiques qui entourent les activités de production des objets métalliques.

Mots clés : culture Moche (Mochica), huacas del Sol y de la Luna (Huacas de Moche), théorie archéologique, spécialisation, artisans, orfèvres

\title{
The craftsman specialization: theory and archaeology. The case of Mochicas metalsmith
}

\begin{abstract}
The craft specialization in prehispanic societies is a subject that ultimately has awakened the interest of the scholars, in the sense that they begin to recognize the assets and direct participation of the craftsmen in the construction of prestige, power and status relationships in the complex societies.

In this time we show the metalsmith case in the Mochica city, from the data that belong to Huacas de Moche site. The information obtained from this site and its comparing, as with contemporary sites as with information associated to other periods of the Peruvian prehistory, let us to approach this subject from perspectives such as technological evolution, constructive characteristics of the metal production areas and the social relationships generated from the political and ideological determining factors that surrounded the metallic objects production activities.
\end{abstract}

Key Words: Moche's (Mochica) culture, Huacas del Sol y la Luna (Huacas de Moche), Theory archaealogy, Specialist, Craftsman, Goldsmith

La sociedad Mochica, desde que fue identificada en el registro arqueológico, a comienzos del siglo XX, hasta la actualidad, no ha dejado de sorprendernos por el alto nivel de complejidad social alcanzado, materializado en imponentes templos, grandes obras de irrigación y en la extraordinaria calidad técnica y artística de sus objetos artesanales, los que formaron parte de los distintos rituales, ceremonias litúrgicas y eventos funerarios celebrados, donde la presencia o ausencia de cada uno de ellos guardaba un especial significado.

Sin embargo, detrás de este repertorio de piezas arqueológicas que hoy admiramos, estuvo un grupo de personas que dedicaron gran parte de su vida a la manufactura de dichos objetos. A ellos hoy la teoría arqueológica-antropológica los reconoce como los especialistas (Redman, 1990). Se trata, pues, de gente que estuvo dedicada a la producción artesanal en sus distintas modalidades, sea en la elaboración de ceramios, textiles, abalorios, trabajos en madera o en metal. En esta oportunidad intentaremos abordar el tema a partir de los rastros dejados por uno de estos grupos especializados: los orfebres del Moche Viejo ${ }^{1}$.

${ }^{1}$ Moche Viejo es el nombre dado por los pobladores del actual distrito de Moche a la antigua urbe enterrada en el yacimiento arqueológico Huacas de Moche. 
El complejo arqueológico Huacas del Sol y de la Luna o Huacas de Moche, se ubica en la parte baja del valle de Moche, al pie y oeste del cerro Blanco, una de las montañas aisladas que domina esta parte del valle. Se trata de un centro urbano ceremonial, que entre los años 400 d.C. a 600 d.C. tuvo el rol de capital del estado Moche sureño. Este centro urbano se compone de dos edificios públicos mayores denominados Huacas del Sol, ubicado en el lado oeste del complejo, y Huaca de la Luna, en el lado este y al pie del cerro Blanco. Entre estos edificios se extiende una compleja y bien tramada red de callejones y plazas que delimitan bloques constructivos a la manera de las manzanas modernas; en estos bloques se erigieron viviendas multifuncionales con áreas de producción artesanal, administrativas y de servicios. Huaca de la Luna se encuentra separada de este conjunto de viviendas por la presencia de dos avenidas de aproximadamente 16 metros de ancho. Los estudios aquí realizados (Uceda \& Tufinio, 2003) indican que se trata de un templo donde se realizaban ritos y ceremonias (en particular sacrificios humanos) que estaban destinados al culto, a la fertilidad agraria y social, así como a crear los mecanismos que legalicen el poder de las élites Mochicas. Sobre Huaca del Sol, sabemos que fue construida tardíamente y se supone que pudo ser un templo palacio con funciones administrativas.

Desde hace ya algún tiempo, los arqueólogos involucrados en estudios sobre la sociedad Mochica tenemos claro que el sitio Huacas de Moche fue una prestigiosa ciudad que logró desarrollar elevados niveles de complejidad en lo que a organización sociopolítica se refiere (Chapdelaine, 2001; 2003; Uceda, 2004). Hoy sabemos que en esta urbe vivieron los personajes de las más altas esferas sociales del valle de Moche, quienes tenían a su cargo las principales actividades de orden político, religioso, administrativo y posiblemente militar. Estos dignatarios presidieron las ceremonias más significativas y relevantes de la época desde los más imponentes templos y edificios construidos en la región, portando los estandartes y símbolos ideológicos que sustentaban su posición social y naturaleza divina, y ataviados con suntuosas parafernalias que exteriorizaban su riqueza y mayor capacidad de acceso a los recursos primarios y bienes suntuarios. Es en este contexto que analizaremos el papel desempeñado por los especialistas orfebres en la construcción de la identidad de tales personajes y, a partir de las evidencias arqueológicas disponibles, examinaremos las relaciones mantenidas por los productores metalurgos y las distintas jerarquías sociales que se presume convivieron en este centro urbano.

\section{LA PRODUCCIÓN METALÚRGICA EN LA COSTA NORTE PREHISPÁNICA A TRAVÉS DEL TIEMPO}

Los restos arqueológicos provenientes del sitio Huacas de Moche relacionados con la producción metalúrgica son un importante complemento al corpus de información acumulado referente a esta actividad desde épocas muy tempranas. En razón de ello se hace necesario comparar y contrastar los datos obtenidos en Huacas de Moche con las fuentes históricas, iconográficas y con los registros arqueológicos de yacimientos contemporáneos y de otros periodos con el objetivo de tener una aproximación a las continuidades y cambios que sufrieron las dinámicas de producción, técnicas de manufactura e instrumental utilizado en la elaboración de objetos de metal a través de más de 1500 años. Si bien se trata de observaciones aun preliminares, dado que nos hemos basado principalmente en información proveniente de la costa norte, es posible arribar a algunas observaciones de orden tecnológico y evolutivo.

\section{LAS PRIMERAS FUENTES}

Como primer recurso en este análisis recurrimos a las primeras fuentes documentales escritas durante la época de la conquista española; a través de ellas es que se obtuvieron los primeros indicios de los procesos de manufactura de objetos metálicos en el Perú antiguo. Estos primeros documentos describen la actividad metalúrgica de la época haciendo referencia en más de una oportunidad a los procedimientos seguidos en las labores orfebres. 
En base a los escritos de Garcilaso de la Vega, Ravines (1978) señala que para fundir el cobre los indígenas no se servían de hornos, sino que introducían el mineral en hoyos practicados en el suelo o en pequeños crisoles, hechos de tierra cocida y polvo de carbón que simplemente eran puestos al fuego, constantemente atizado por cierto número de hombres con sus pucuna, que soplaban las brasas hasta que obtenían el calor requerido.

«No supieron limas ni buriles; no alcanzaron a hacer fuelles para fundir. Fundían a poder de soplos con unos canutos de cobre, largos de media braza más o menos, como era la fundición grande o chica. Los canutos cerraban por el un cabo, dejábanle un agujero pequeño por donde el aire saliese más recogido y más recio. Juntábanse ocho, diez y doce, como era menester para la fundición, andaban alrededor del fuego soplando con los canutos, y hoy estan en lo mismo que no han querido mudar costumbre. Tampoco supieron hacer tenazas para sacar el metal del fuego: sacábanlo con unas varas de palo o cobre, y echábanlo en un montoncillo de tierra humedecida que tenían cabe si para templar el fuego del metal: allí lo traían y revolcaban de un cabo a otro, hasta que estaba para tomarlo en las manos». (Garcilaso de la Vega, 1943 [1609]: 126)

Una vez obtenido el metal fundido, la elaboración de los objetos se realizaba por varios métodos. El más simple y primitivo, puesto que viene de la utilización de metales en estado nativo, fue indudablemente el de «majar el metal en forma requerida hasta reducirlo a delgadas láminas fácilmente maleables, utilizando martillos sin mango, llamados lihuanas, hechos generalmente de sílex negro. Operación posible de realizar cuando los metales son puros y blandos». (Ravines, 1978: 480)

Girolamo de Benzoni, a partir de sus observaciones en la cuidad de Quito durante el siglo $\mathrm{XVI}$, ofrece otra importante descripción del proceso de producción metalúrgica, cuya parte más relevante transcribimos a continuación:

«Esa provincia de Quito es de aire templado, por lo cual los reyes del Cuzco vivían allí la mayor parte del tiempo, manteniendo en muchos sitios casas de orfebres, los que sin conocer el uso de ningún instrumento de fierro, toscamente labrando hacian cosas maravillosas procediendo en su trabajo de esta manera.

En primer lugar cuando funden el oro y la plata, colocan el metal en un crisol largo o redondo, hecho de un pedazo de trapo embadurnado con tierra mojada y carbón machacado; una vez que el crisol está seco lo ponen al fuego con la cantidad de metal que pueda caber en el, y con cinco canutos de caña; ora más ora menos, tanto soplan que éste termina por fundirse y colar; luego, sentados los orfebres en el suelo, con unas piedras negras confeccionadas para esta clase de labor, ayudándose uno al otro, hacen, o mejor decir hacían en la época de su prosperidad, lo que se les había mandado confeccionar, esto es estatuas vacías, vasos, ovejas, joyas y en fin toda suerte de figuras de los animales que se podían ver». (Benzoni, 1967 [1565]: 263)

Las fuentes iconográficas también han sido útiles para los estudios de este tema, así podemos citar el análisis que hace Donnan $(1973 ; 1998)$ de un ceramio Mochica donde se representaron a 5 personajes realizando actividades relacionadas con la producción de objetos de metal (fig. 1). Tres de ellos aparecen usando sopladores para introducir aire dentro de una cúpula, el cuarto personaje se halla manipulando uno de los objetos que está encima de ella. Se desconoce la posición del quinto personaje debido a que se había desprendido del ceramio, sin embargo, las marcas dejadas por él sugieren que se hallaba sosteniendo algo que estaba en contacto con uno de los elementos rectangulares que aparecen en la superficie de la cúpula, o quizá tocaba uno de ellos para moverlo (Donnan, 1998: 18). También respecto a este ceramio, Carcedo apunta que se trataría de la representación de un horno para el calentamiento de piezas o de moldes; según esta investigadora «no es un horno de fundición (...) pues (...) el proceso es muy diferente» (Carcedo, 1992: 287). La posición de Carcedo está apoyada en los datos obtenidos en Batán Grande (Shimada et al., 1982), donde la evidencia arqueológica de hornos de fundición es muy distinta a la que aparece graficada en el ceramio Mochica presentado por Donnan. No obstante 


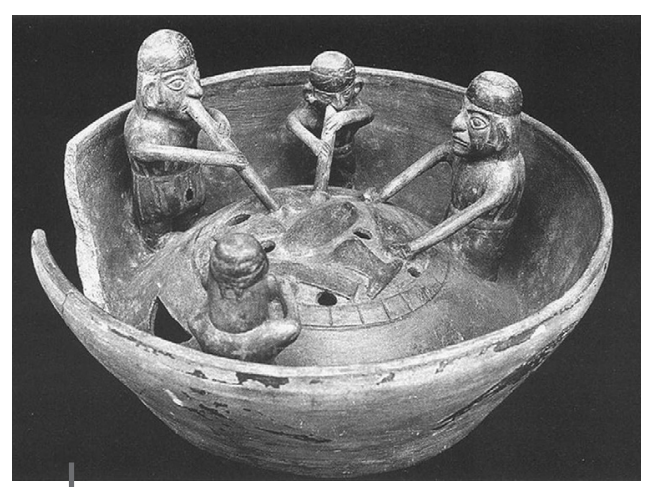

Figura 1 - Ceramio Mochica que exhibe una escena de producción metalúrgica (tomado de Donnan 1998)

se debe remarcar que la evidencia de Batán Grande corresponde a un periodo posterior al Mochica.

\section{LOS CONTEXTOS ARQUEOLÓGICOS}

Después de un siglo de práctica arqueológica en el Perú, y sobre todo gracias a los trabajos ejecutados en los últimos 20 años, hoy en día estamos en condiciones de complementar los datos históricos e iconográficos presentados líneas arriba con estudios arqueológicos relacionados con la producción especializada en las sociedades prehispánicas. Los hallazgos de talleres de diversa índole y los estudios referentes a las técnicas de manufactura desarrolladas por los antiguos pobladores andinos a través de su historia pueden permitirnos constatar y contrastar las fuentes anteriormente mencionadas. En esta oportunidad haremos una breve revisión de los principales trabajos relacionados con los talleres y áreas de producción metalúrgica, sobre todo en la costa norte peruana.

La evidencia más temprana de la existencia de talleres de metalurgia fue reportada por Grossman (1972), quien halló los testimonios más antiguos de labor orfebre en el Perú en la localidad de Waywaka, Andahuaylas. Entre el material encontrado se menciona finas laminillas de oro y un juego de herramientas para trabajar el metal, asociado a contextos funerarios fechados alrededor de 1500 a. C.

Para el periodo Formativo (circa 2000 a.C.-200 a.C.), a pesar de la abundante evidencia de producción metálica, no existe un contexto claro de los talleres donde se fabricaron estos objetos. Sin embargo, en base a las colecciones existentes ha sido posible hacer una revisión de la actividad orfebre durante el periodo Formativo, acerca de la cual Alva (1992) señala que los orfebres de este periodo elaboraron un repertorio de objetos con formas básicas que mantuvieron su continuidad a través del tiempo.

«Los orfebres inician y mantienen indeclinablemente sus técnicas de trabajo martillando y laminando el metal. La lámina plana, luego repujada, doblada, rolada, grabada, unida mecánicamente o por soldadura, constituyó el elemento básico de toda labor orfebre, pudiendo ir desde placas relievadas a esculturas huecas». (Alva, 1992: 114)

Por otra parte, se cuenta con trabajos bien documentados referentes a la producción metalúrgica durante el periodo Intermedio Temprano (circa 100 a.C.-650 d.C.), algunos de éstos podrían correlacionarse temporalmente con la evidencia obtenida en Huacas de Moche. Así tenemos el realizado por Diez-Canseco (1994) quien nos ofrece importantes datos acerca de la producción de objetos de metal en el sitio de Vicús, en el Alto Piura (Makowski et al., 1994), específicamente en la Pampa Juárez, al sureste del Cerro Vicús. Se trata de un pequeño taller orfebre donde halló evidencia de un horno de fundición asociado a dos fogones usados para el recalentamiento de las «perlas de metal» (prills), que posiblemente eran de cobre puro. Previamente, estas «perlas» fueron separadas de la escoria moliéndolas en batanes para luego ser fundidas en crisoles formando «tejuelos y se procedió a darles forma recalentándolos en los fogones, laminándolos con martilleo sucesivo. En el caso de los objetos vaciados, el metal fundido se vertía en moldes» (Diez-Canseco, 1994: 193). Entre el material recuperado de este taller se tiene miniaturas de arpones, agujas, alambres, lentejuelas, tiestos con escoria adherida y prills. Estos datos coinciden con aquellos análisis que señalan que casi todos los objetos metálicos provenientes de Loma Negra fueron hechos martillando láminas de metal, cobre en la mayoría de los casos (Lechtman et al., 1982). 
Bourget (2003) también reporta brevemente en Huancaco, en el valle de Virú, evidencia de trabajos de metalurgia. Según este autor, el sector V-316 podría tratarse de un taller de fundición de metales con pequeñas estructuras para depósitos. Lamentablemente, el autor no proporciona mayores detalles y habrá que esperar una publicación donde los contextos y materiales sean presentados en forma extensa.

En el sitio Mochica Tardío de Pampa Grande, las excavaciones dirigidas por Kent Day permitieron determinar que la estructura 52 del Sector $\mathrm{H}$ funcionó como taller de metalurgia donde se forjaba el cobre dándole la forma deseada, se recalentaba y martillaba (Shimada, 1994; 2001). Dicho taller se situaba adjunto a un estrecho corredor y consistiría en 4 ambientes interconectados pero funcionalmente diferentes. Se trataría de un taller de orfebrería que era aprovisionado con lingotes de cobre traídos de áreas de fundición aún no identificadas. Shimada sustenta que los restos de vasijas finas en este taller reflejan la presencia personal de la élite supervisando los trabajos de los orfebres, es decir, las labores eran dirigidas por pocos especialistas y varios asistentes o aprendices (Shimada, 2001). Cabe anotar que tanto éste como los demás centros de producción registrados en Pampa Grande se hallan inmersos dentro de una compleja red urbana, donde a la vez funcionaron residencias, centros administrativos y templos de culto.

Para fechas posteriores como el Horizonte Medio (circa 700 d.C.-1100 d.C.) y el Periodo Intermedio Tardío (circa 1100 d.C.-1400 d.C.), tenemos las investigaciones que Donnan (1990) reporta para Huaca Chotuna, valle de Lambayeque, donde la producción metalúrgica se habría practicado durante un largo período de tiempo (aproximadamente desde 400 d.C. hasta 1600 d.C.). Entre los objetos encontrados se tiene agujas, pinzas y ornamentos personales. Este investigador señala que, ante la no existencia de indicadores que prueben que en este sitio se hubieran realizado labores de fundición, es probable que los prills trabajados en Huaca Chotuna fueran fundidos en Batan Grande como parte de una red de intercambios dentro de la misma región, por lo tanto, aparentemente, aquí se habrían realizado exclusivamente labores de orfebrería.

Precisamente, uno de los sitios que mejor evidencia ofrece respecto a producción metalúrgica es el complejo arqueológico de Batan Grande, específicamente el sector III de Cerro de los Cementerios, valle de La Leche, señalado por sus investigadores como el mayor centro regional proveedor de aleaciones de lingotes de cobre y posiblemente implementos para la producción orfebre durante un periodo de tiempo que abarcó desde el 950 d.C. hasta 1530 d.C. aproximadamente (Shimada et al., 1982). En base a la evidencia obtenida, se ha hecho un valioso intento de reconstrucción de las técnicas usadas para la extracción de prills de cobre y la fundición de este metal a gran escala. Entre la evidencia registrada se tiene una gran cantidad de hornos de fundición, los cuales estaban asociados a estructuras arquitectónicas. De otra parte, se ha señalado que una de las posibles razones que llevaron a los antiguos metalurgos a escoger este sector como centro principal de sus actividades fueron las favorables condiciones climáticas: el viento sopla constantemente en una dirección y éste puede ser predecible, sobre todo en las tardes (Shimada et al., 1982: 955). Asimismo, también se especulan otros factores como la ubicación central del cerro entre varias vías de comunicación que permitían la fácil accesibilidad a la gran cantidad de recursos existentes en las minas prehistóricas del valle.

Para épocas Chimú, contamos con la evidencia de los talleres reportados en Chan Chan expuestos por Topic (1990). Los restos de lingotes de cobre abandonados por los artesanos y otros hallazgos sustentan que en estos espacios se recalentaban los restos de cobre para obtener lingotes. Topic expone el caso del taller ubicado en el SIAR cercano a la ciudadela Laberinto, donde las áreas de producción metalúrgica se entremezclaban con las áreas residenciales y administrativas, hecho que el autor interpreta como evidencia de que hubieron maestros artesanos supervisando a otros artesanos de menor rango (Topic, 1990), similar al caso planteado en Pampa Grande por Shimada (2001). Asimismo sostiene que los especialistas que habitaron dicha capital vivían en barrios residenciales, al interior de los cuales los artesanos fueron distribuidos en grupos familiares, con áreas de cocina, depósitos, espacios para realizar su trabajo y para tener animales domésticos. En muchas de estas viviendas se habrían realizado al mismo tiempo trabajos de 
metalurgia y textilería, razón por la que este autor propone que los adultos, tanto masculinos como femeninos, fueron artesanos, hecho que también recibe el sustento de las fuentes etnohistóricas e iconográficas. Según Topic (1990), la producción artesanal realizada en la capital Chimú proveyó a la élite de Chan Chan de una fórmula efectiva de mantener su status sobre los señores de las provincias, logrando favorables condiciones de paz, relaciones comerciales y de dependencia económica.

Finalmente tenemos las excavaciones realizadas por Guerrero en el cementerio Inca del sitio Rinconada Alta, valle bajo del Rímac (in Carcedo \& Vetter, 2002). Los resultados obtenidos revelaron valiosa información acerca de las prácticas funerarias dedicadas a artesanos durante el Horizonte Tardío (1400 d.C.-1532 d.C.) en la costa central. Una de las más impresionantes características de este cementerio es que estaba dividido por sectores, uno de los cuales estuvo íntegramente dedicado al entierro de especialistas, lográndose diferenciar artesanos relacionados con la producción de textiles, cerámica y metales. La asignación de los entierros a diferentes tipos de artesanos ha sido planteada por los autores a partir de los ajuares funerarios que acompañaron y distinguieron las actividades a las que estuvieron relacionados estos individuos (Guerrero in Carcedo \& Vetter, 2002).

Carcedo \& Vetter llevaron a cabo el análisis de los objetos e instrumental metálico provenientes de este sitio asociados con los sectores dedicados al entierro de orfebres y a basurales cercanos, arribando a importantes conclusiones. Según estas investigadoras, la gente enterrada en el Sector IIA del cementerio no pertenecía a una población Inca, sino que pudo tratarse de un grupo de orfebres subordinados al régimen incaico, los cuales cumplían con el mandato de fabricar piezas de metal como parte del tributo al trabajo artesanal especializado. Del mismo modo señalan que cada orfebre tenía su propio juego de instrumentos para la fabricación de las piezas de metal; era de vital importancia que cada orfebre fabricase sus propios instrumentos para su uso personal para evitar «las maldiciones o mañoserías que traerían estas herramientas si pertenecieron anteriormente a otro orfebre». (Carcedo \& Vetter, 2002: 65)

De este repaso podemos discutir dos aspectos puntuales, por un lado vemos que aparentemente no hubo cambios radicales en las características arquitectónicas y espaciales de los talleres orfebres, por lo menos desde el Intermedio Temprano hasta el Intermedio Tardío. Si observamos los planos de planta de los talleres de Chan Chan, Pampa Grande y Huacas de Moche veremos que las dimensiones son muy similares, cuentan con pequeñas estructuras que sirvieron como depósitos y se encuentran adjuntos a áreas de circulación, espacios públicos y a otros talleres, todos ellos inmersos en un contexto urbano-productivo (fig. 2).

De otro lado también se observan pocos cambios en lo que respecta a la cadena productiva en la fabricación de objetos metálicos y en el instrumental utilizado en estas labores, siendo recurrente la presencia de martillos, yunques, punzones, prills y crisoles en el registro de los talleres orfebres andinos. Con referencia a la cadena de producción metalúrgica cabe indicar que ésta consta de tres procesos básicos, los cuales pueden presentar variantes de acuerdo al tipo de materia prima de origen (Levin, 1994: 22-24):

1. Extracción de la materia prima, sea mediante lavaderos o socavones.

2. La extracción del metal de los minerales. Para ellos el primer paso es la molienda. Luego, dependiendo del tipo de mineral, se hace la reducción de los carbonatos u óxidos. Para este procedimiento se requiere hornos con temperaturas superiores a los $700^{\circ} \mathrm{C}$, o se procede a la fusión oxidante o a la fundición que requieren temperaturas superiores a los $1000^{\circ} \mathrm{C}$. En ambos procesos producen escorias abundantes.

3. La fabricación. El metal en lingote es transformado en objetos mediante diversos procesos metalurgísticos tales como: el laminado por martillado, el templado o recocido, el recopado, granulado. Asimismo se emplearán diversas técnicas para lograr los decorados, entre ellos tenemos el embutido, dorado y plateado, engastado, etc.

Esta cadena productiva no necesariamente se va a encontrar en un mismo lugar, por lo general los procesos de oxidación o carbonatación y fundición se realizaron en áreas cercanas a las zonas 
Santiago Uceda Castillo, Carlos E. Rengifo Chunga
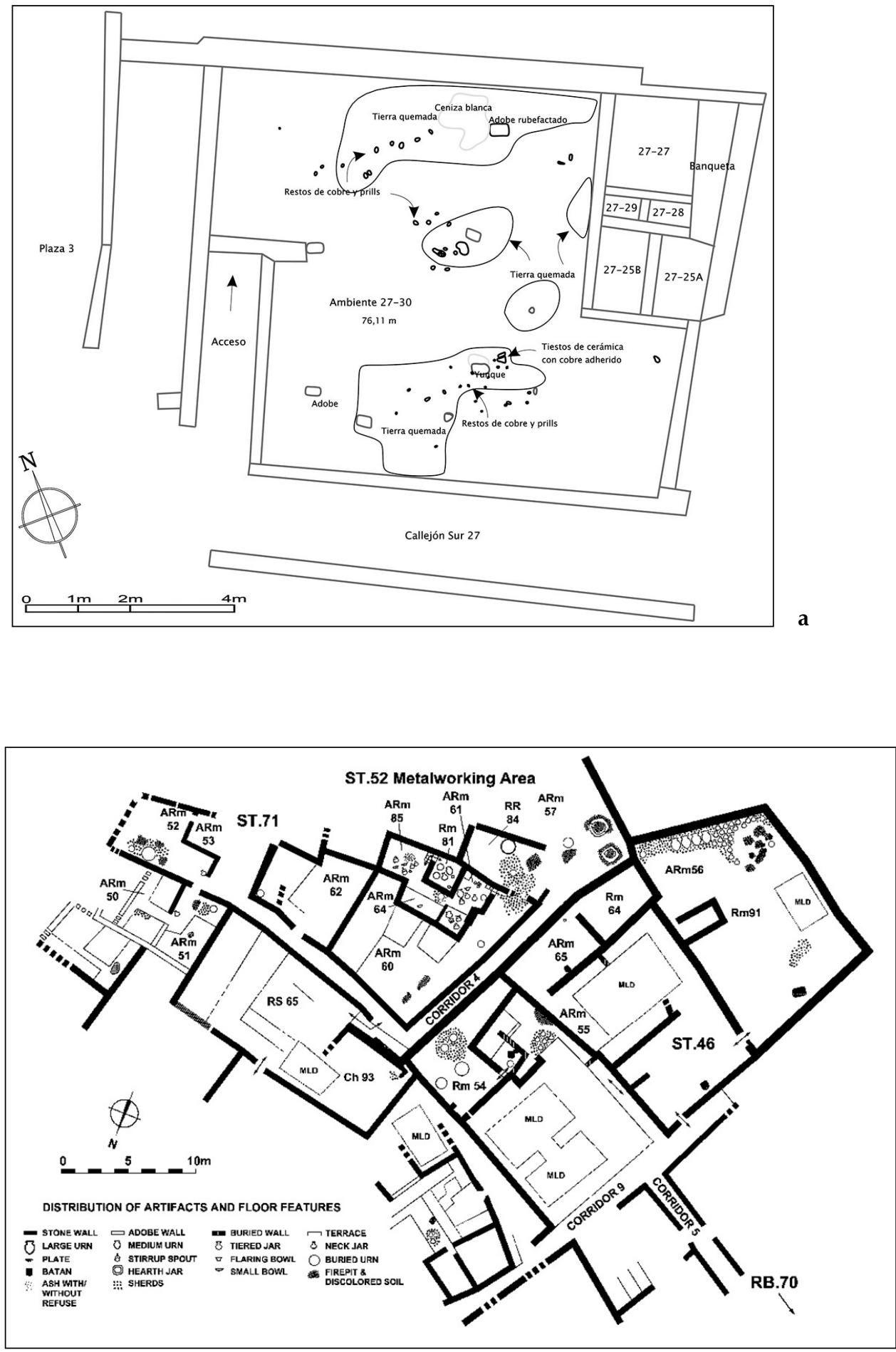


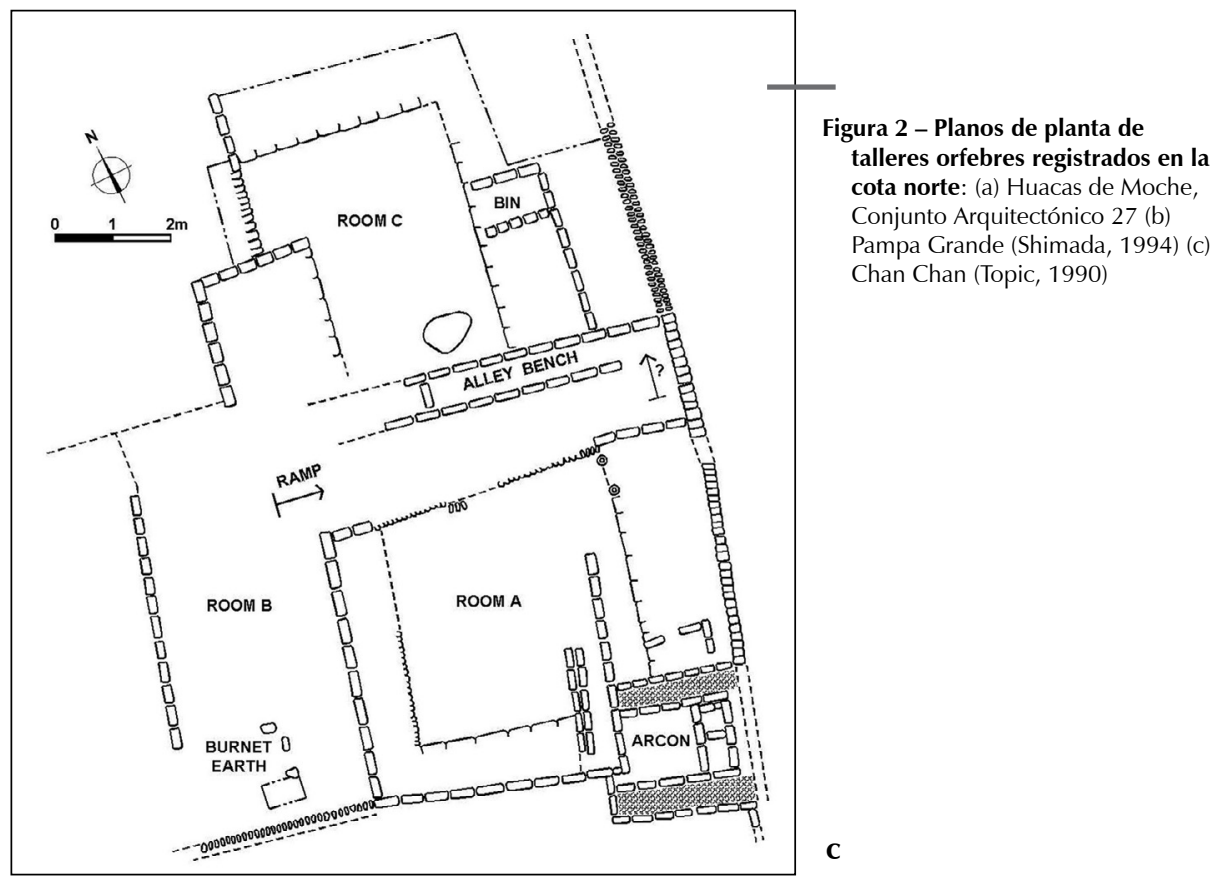

de extracción del mineral, mientras que los procesos de elaboración de artefactos se realizaron en los centros urbanos.

Obviamente vamos a observar diferencias entre un objeto metálico del siglo VI y otro del siglo XII, pero a la luz de los datos arqueológicos expuestos, es posible que ambos sean el resultado final de una dinámica de producción muy similar. Los cambios se dieron básicamente en las formas y símbolos icnográficos producidos, lo que respondería a los diferentes contextos sociales imperantes en cada época, donde entraron en juego factores de dominación y negociación entre los especialistas y las élites o de demanda de algunos objetos suntuarios y utilitarios en particular por parte de la clase media y de otro tipo de productores.

\section{EL CONTEXTO DE LAS PIEZAS METÁLICAS DEL SITIO HUACAS DE MOCHE: UN POCO DE HISTORIA}

Es sabido que uno de los principales motivos que impulsó a los españoles del siglo XVI a explorar las tierras del Tahuantinsuyo fueron las noticias que recibieron acerca de la existencia de un territorio donde abundaba el oro y la plata. Fue así que los trabajos en metalurgia realizados por el hombre andino alcanzaron tempranamente fama en el viejo mundo. Los documentos de la época señalan que la costa norte peruana fue una de las principales regiones donde los españoles ejercieron un agresivo proceso de saqueo y destrucción de los templos, santuarios y mausoleos de los cuales extraían, entre otras cosas, cotizados telares y piezas de metal (Ramírez, 2002).

Sería tiempo después, a inicios del siglo XX, cuando Max Uhle (Kroeber, 1925) hizo el primer reporte científico de una importante colección de piezas metálicas provenientes de una plataforma 
adjunta a Huaca de la Luna, colección que actualmente se encuentra bajo la custodia del R. H. Lowie Museum of Anthropology, Berkeley. Medio siglo después, Rafael Larco (2001) encabezó intensivas excavaciones en el sitio registrando varios contextos funerarios que contenían objetos de metal como parte del ajuar funerario. Posteriormente, en la década de 1970, como parte de los trabajos de campo realizados por el Proyecto Chan Chan-Valle de Moche, también se registraron varias piezas de metal que formaban parte de las ofrendas depositadas en las tumbas del sitio (Donnan \& Mackey, 1978).

Sin embargo, a pesar de los varios documentos que reportaban una importante cantidad de objetos metálicos provenientes de las Huacas de Moche, el hecho de que tales piezas hubiesen sido fabricadas en el mismo sitio era solo una sospecha. No se había hallado aún un contexto que pruebe de manera contundente que la producción metalúrgica se llevaba a cabo en este mismo lugar, dado que tampoco se conocía las características urbanas de este complejo arqueológico. Sería recién a partir de 1991, con el Proyecto Huaca de la Luna, que se comenzó un ciclo de sucesivas campañas de excavaciones a partir de las que se hicieron importantes descubrimientos de talleres articulados dentro de una de las más complejas redes urbanas de carácter productivoresidencial (Uceda et al., 1997; 1998; 2000; 2004).

\section{LAS EXCAVACIONES EN EL NÚCLEO URBANO... PLANIFICACIÓN, DISEÑO Y PRODUCCIÓN}

Uno de los principales objetivos planteados por el Proyecto Huaca de la Luna ha sido abordar el problema de las relaciones sociales y políticas mantenidas entre la clase urbana y los gobernantes que residían en el sector adjunto al templo Huaca de la Luna (Uceda, 2004). En este esfuerzo cotejamos los datos obtenidos de las excavaciones tanto en el área sacra como en el núcleo urbano, logrando alcanzar resultados que nos aproximan con éxito a la configuración de la trama urbana del sitio, al menos durante los años 600 d.C. al 800 d.C., periodo de tiempo que se correlaciona con la predominante presencia del estilo cerámico Moche IV de la secuencia de Larco (1948) (fig. 3).

Hoy en día sabemos que el diseño, ubicación y ordenamiento de los espacios arquitectónicos residenciales, públicos y productivos respondían a un planificado trazo de planta ortogonal, que se cimentaba en la presencia de elementos ordenadores tales como las grandes vías de circulación que convergían en espacios abiertos o plazas públicas. Al interior de los espacios residenciales se mantuvo este mismo patrón usando pasadizos y corredores menores. Por otra parte, el dato arqueológico recuperado al interior de cada ambiente, y su posterior correlación con las áreas adyacentes a los mismos, nos ha permitido determinar la función de cada uno de dichos espacios, logrando identificar sectores de orden doméstico, ceremonial y talleres de producción (Tello et al., 2004a; 2004b; Chiguala et al., 2004).

Antes de la década de 1990, el único indicio de la existencia de talleres productivos en el sitio Huacas de Moche fue ubicado al pie de Huaca del Sol, donde se registró una concentración de turquesas bajo la forma de cuentas, preformas y fragmentos no trabajados (Topic, 1977). Con el inicio de las excavaciones en el núcleo urbano, se fueron documentando paulatinamente sectores de producción de cerámica fina (Armas 1999; Uceda \& Armas, 1997; 1998) y cerámica doméstica (Jara, 2000), áreas de preparación de chicha (Chapdelaine, 2001; 2003; Gamarra et al., 2004), espacios de manufactura de ornamentos corporales y trabajos en piedra (Bernier, 1999; Chapdelaine et al., 2000; Chiguala et al., 2006); sectores que posiblemente sirvieron para la fabricación y almacenamiento del material textil (Chapdelaine, 2001; 2003) y áreas relacionadas con la producción de objetos metálicos (Chapdelaine, 1998; 2003; Chapdelaine et al., 2001; Chiguala et al., 2004; Rengifo, 2005; Rengifo \& Rojas, 2005; ms). 
La especialización del trabajo: teoría y arqueología. El caso de los orfebres Mochicas

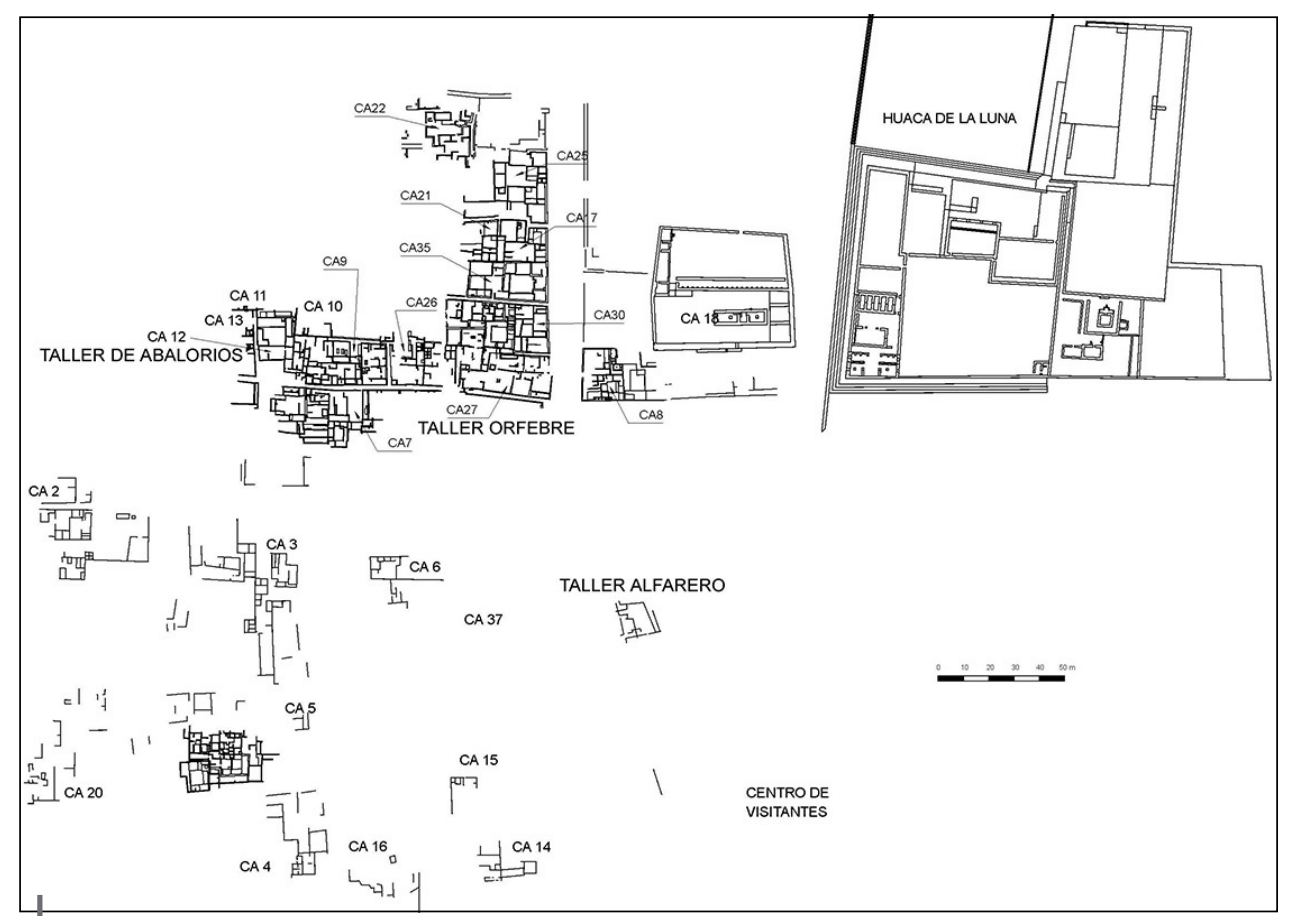

Figura 3 - Sectores excavados en el núcleo urbano del Complejo Arqueológico Huacas de Moche

\section{ORFEBRES EN EL MOCHE VIEJO: LA EVIDENCIA ARQUEOLÓGICA}

La evidencia de áreas de producción metalúrgica en Huacas de Moche se sostiene en los hallazgos de un horno de fundición en el Conjunto Arquitectónico 7 (Chapdelaine, 2003) y un taller orfebre registrado en el Conjunto Arquitectónico 27 (Rengifo, 2005; Rengifo \& Rojas, 2005).

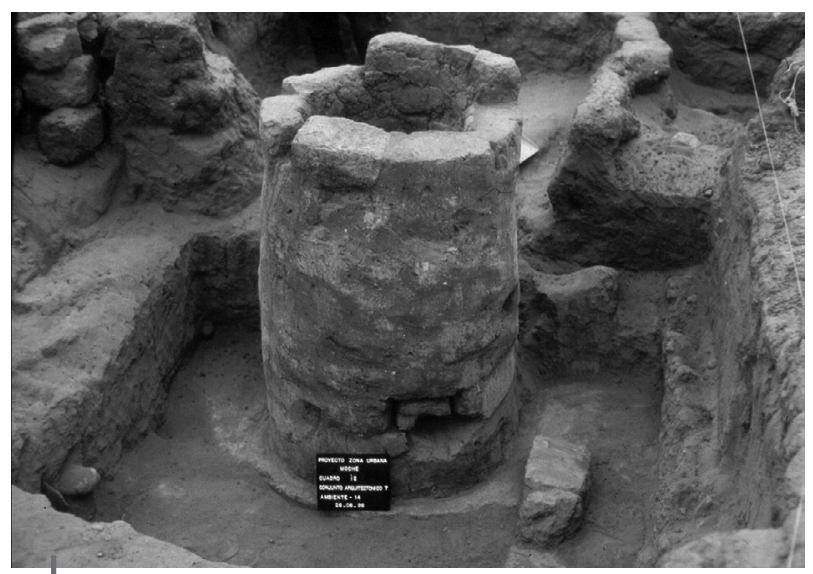

Figura 4 - Horno para la fundición de metales registrado en el Conjunto Arquitectónico 7
Con referencia al primero Chapdelaine señala, en base a las diferentes capas registradas al momento de la excavación, que la estructura «fue preservada aun cuando el sector sufrió varias ocupaciones luego del momento de su destrucción» (Chapdelaine, 1998: 93) (fig. 4). Durante la excavación de este horno se registraron, asociados a un piso de adobes, carbones de madera y fragmentos enrojecidos de mortero mezclados con ceniza.

«La construcción de esta chimenea fue realizada superponiendo nueve filas de adobes de manera circular para obtener un diámetro 
interior de $55 \mathrm{~cm}$. La altura de la chimenea alcanza 1,20 m (...), se encontró una pequeña abertura cerca de la base. Este pequeño orificio, de 15 por $15 \mathrm{~cm}$, estaba tapado por un adobe esculpido someramente que servía para bloquear la abertura». (Chapdelaine, 1998: 93)

Si bien en un primer momento esta estructura fue denominada como «chimenea», posteriormente se realizaron análisis de activación neutrónica aplicados a dos muestras de mortero provenientes de este hallazgo. Los resultados arrojaron una importante presencia de partículas de oro y cobre, lo que se usó como evidencia para sostener que se trataba de un horno usado para la fundición de metales (Chapdelaine, 2003).

\section{EL BLOQUE ARQUITECTÓNICO 27-30}

Durante la temporada 2003, como parte de los trabajos que se realizan en el núcleo urbano del complejo Huacas de Moche, se excavó el Conjunto Arquitectónico 27 con el objetivo de determinar la dinámica ocupacional de sus 3 últimos momentos de uso. Sin embargo, dadas las desfavorables condiciones de conservación que sufrieron las 2 últimas ocupaciones por agentes naturales y culturales, la investigación se centró en la antepenúltima fase de ocupación (Chiguala et al., 2004; Gamarra et al., 2004).

Como resultado de dicha investigación se logró determinar la existencia de distintos ambientes y/o espacios arquitectónicos al interior de los cuales se desarrollaron actividades de orden doméstico, productivo y ritual. Éstos estaban a su vez interconectados a través de vías de circulación menores, tales como pasadizos, vestíbulos y patios. Complementariamente, al cotejar los datos obtenidos de las excavaciones en el Conjunto Arquitectónico 27 con las del Conjunto Arquitectónico 30, donde anteriormente se había llegado hasta el mismo nivel ocupacional (Tello et al., 2000), se advirtió la configuración de un solo bloque arquitectónico, el cual puede entenderse como lo que hoy en día conocemos como una manzana residencial. Es así que, a partir de los resultados alcanzados en ambas temporadas, se sostiene que, durante el periodo asociado a la fase estilística Moche IV de Larco (1948), los Conjuntos Arquitectónicos 27 y 30 funcionaron como un solo bloque arquitectónico, el cual además se trataría de la residencia de una familia de la élite Mochica (fig. 5).

El Bloque Arquitectónico 27-30 se subdivide a su vez en lo que hemos venido a denominar sub-conjuntos, que vienen a ser sub-sectores o sub-divisiones al interior del mismo complejo arquitectónico, separados por muros anchos cuya construcción y diseño es anterior al momento de ocupación que estamos tratando. Estos subconjuntos presentan distintas dimensiones y disposiciones arquitectónicas relacionadas con las actividades realizadas al interior de cada uno de los mismos. Así, refiriéndonos al Bloque Arquitectónico 27-30, podemos distinguir dos grandes sectores claramente diferenciados. Por un lado tenemos el sector norte, es decir, lo que corresponde al Conjunto Arquitectónico 30, que estuvo dedicado a albergar actividades domésticas. En este espacio se han documentado espacios para descanso y habitación, un patio con banquetas que posiblemente fue usado como lugar de convergencia o reunión, y pequeñas estructuras a manera de depósitos o almacenes. Se trata pues de sector dedicado a la residencia y administración de todo el Bloque Arquitectónico, que podría interpretarse como el área de un grupo corporativo (Uceda, ms).

Por otra parte, el sector sur, que corresponde al Conjunto Arquitectónico 27, aparentemente estuvo más ligado a labores productivas y rituales. En él se identificaron 3 subconjuntos en los cuales se halló evidencia de distintos tipos de actividades. El Subconjunto 1 estuvo relacionado con actividades de descanso y habitación; en el Subconjunto 2 se habrían llevado a cabo labores de preparación de alimentos y producción de chicha; y, finalmente, el Subconjunto 3 fue el que estuvo ligado a las actividades productivas. Precisamente, será éste el subconjunto en el que nos enfocaremos a continuación, dado a que en él se halló evidencia de actividades de producción metalúrgica. 


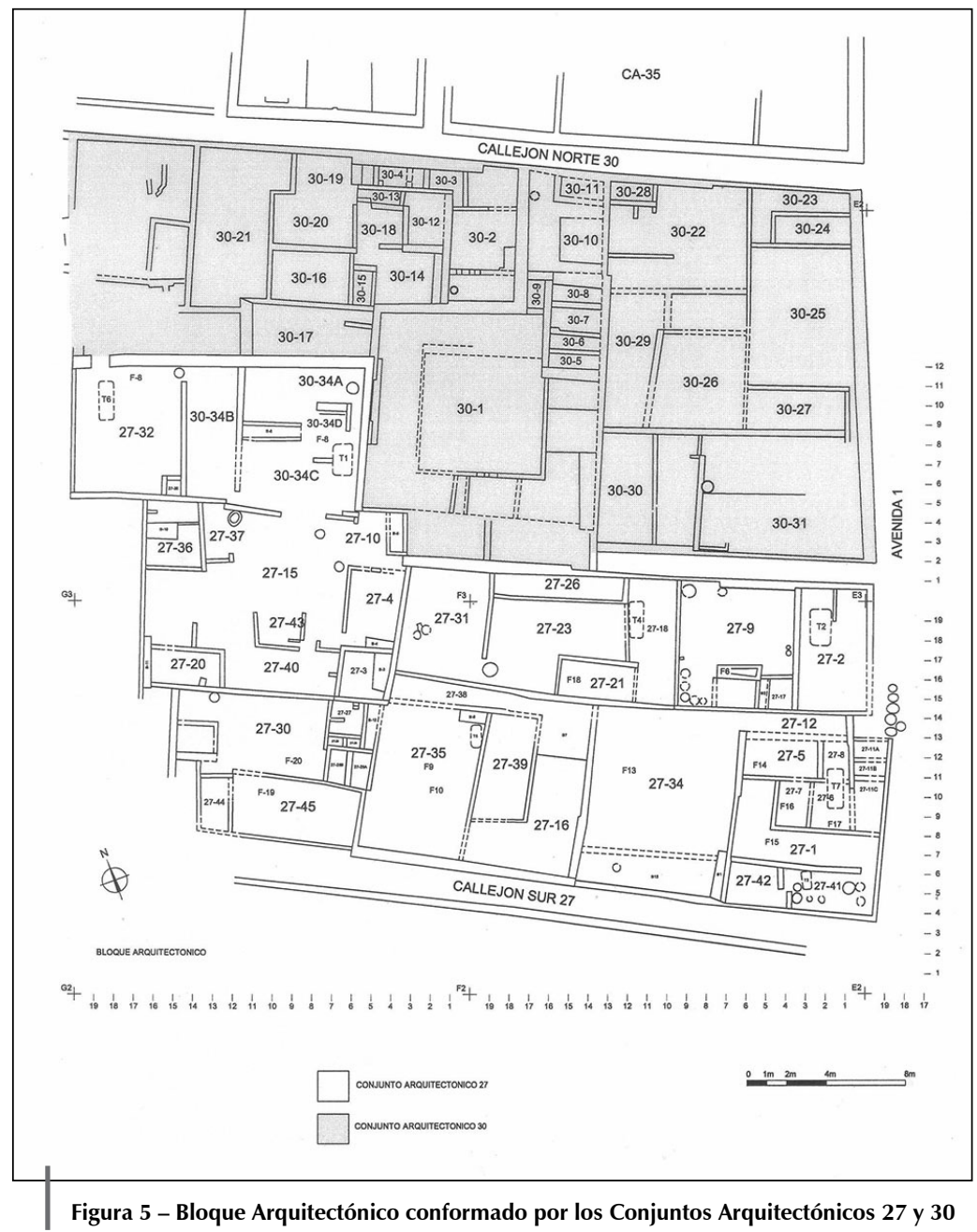

\section{EL TALLER ORFEBRE MOCHICA}

Este taller está ubicado al extremo suroeste del Bloque Arquitectónico 27-30, se trata de un espacio de regular tamaño (7,5 $\mathrm{m}$ de largo por 7,2 $\mathrm{m}$ de ancho promedio) cuyos restos revelan la existencia de un taller relacionado con la actividad metalúrgica. Luego de su excavación se concluyó que durante la penúltima fase de ocupación del conjunto (asociada a la fase estilística Moche IV), en el ambiente 27-30 se habrían realizado trabajos de repujado y martillado de cobre, es decir, trabajos especializados en orfebrería (figs. 6 y 7 ).

A manera de descripción, podemos mencionar que asociado al piso del taller y a su remodelación se halló gran cantidad de escoria de metal, prills, restos de cerámica con cobre adherido (posiblemente se trate de crisoles utilizados para el recalentamiento del metal) y un yunque in situ con claras huellas de uso así como restos de cobre en su superficie y alrededores (fig. 8). El piso presentaba evidencia de fuertes quemas y concentraciones de restos de carbón, lo que seguramente guarda relación con las improntas que quedan luego de recalentar el metal fundido (fig. 9). Las formas 


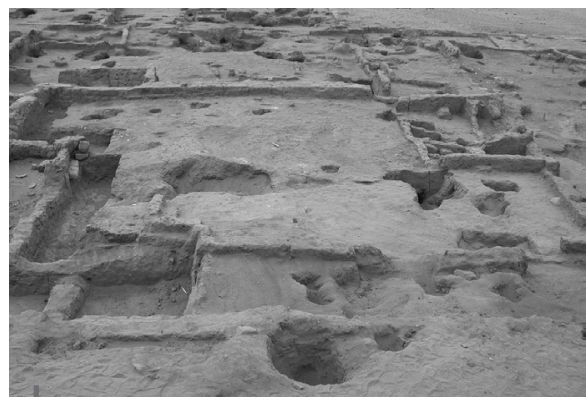

Figura 6 - Taller Orfebre registrado en el Conjunto Arquitectónico 27. Vista de sur a norte durante el proceso de excavación

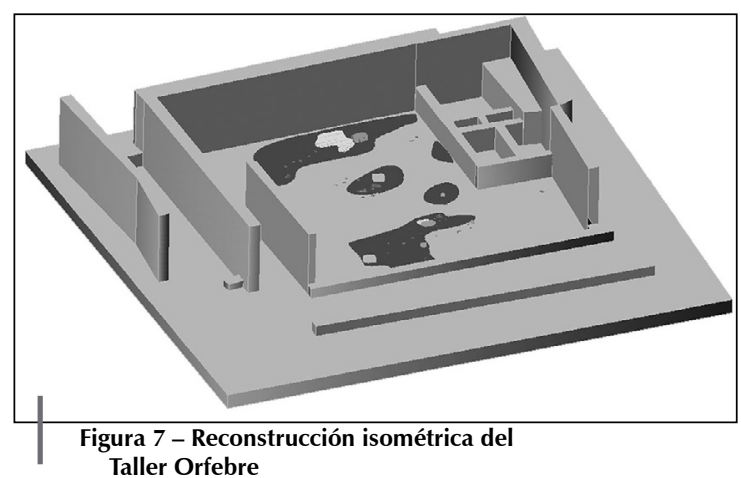

Taller Orfebre

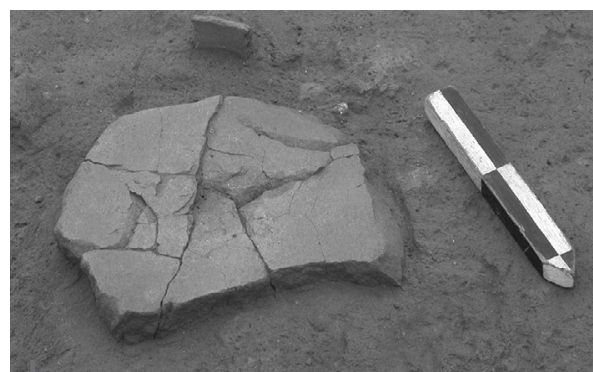

Figura 8 - Yunque in situ hallado en el Taller Orfebre

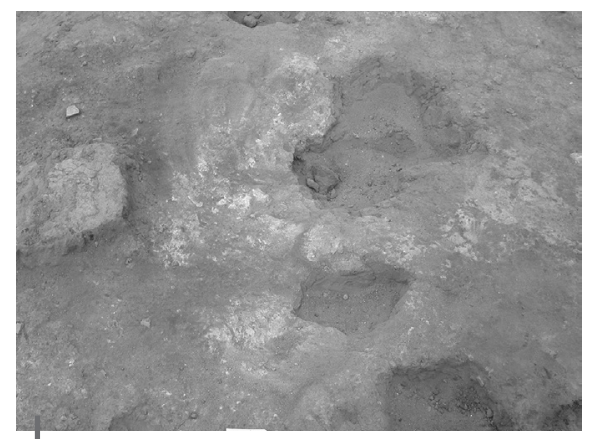

Figura 9 - Huellas de quema en el piso del taller, adobes rubefactados y escoria de cobre

metálicas recuperadas incluyen prills, pequeñas láminas, alambres, agujas, todas en aparente proceso de elaboración o bien formaban parte de objetos con defectos de fabricación (figs. 10 y 11). En esta área también se registraron pequeñas estructuras que pudieron servir como depósitos o almacenes para material trabajado (ambientes 27-25, 27-27, 27-28 y 27-29) (fig. 12) (Rengifo, 2005; Rengifo \& Rojas, 2005). Cabe también anotar que del relleno de este sector se obtuvieron algunos artefactos líticos tales como martillos, percutores y alisadores, así como toberas de cerámica.

Sin embargo, luego de su uso en épocas Mochicas, este contexto se vio alterado por el paso de una escorrentía, de probable filiación Chimú, que corta el ambiente por la mitad destruyendo buena parte de los pisos originales. Sin embargo, al proceder con la limpieza de dicha escorrentía también se halló gran cantidad de material lítico asociado con los trabajos en metal como martillos, pulidores, percutores, así como abundantes restos de cobre (fig. 13). Otros elementos que alteraron el contexto original fueron los grandes pozos de huaquero existentes en este sector.

Durante la antepenúltima ocupación del Conjunto Arquitectónico 27 el taller metalúrgico parece haber estado ubicado en el ambiente 27-15 del Subconjunto 3. Durante la excavación de este espacio se recuperaron elementos similares a los del ambiente 27-30. Es decir, restos de objetos metálicos a medio trabajar, artefactos líticos, fragmentos de crisoles y toberas de cerámica. El mal estado de conservación de este sector no permitió obtener contextos con la misma calidad contextual del ambiente 27-30, sin embargo, dada la cercanía entre estos ambientes y la similitud de su material asociado es posible que el 27-15 hubiese sido el taller metalúrgico asociado a la antepenúltima fase ocupacional del Bloque Arquitectónico 27-30. 


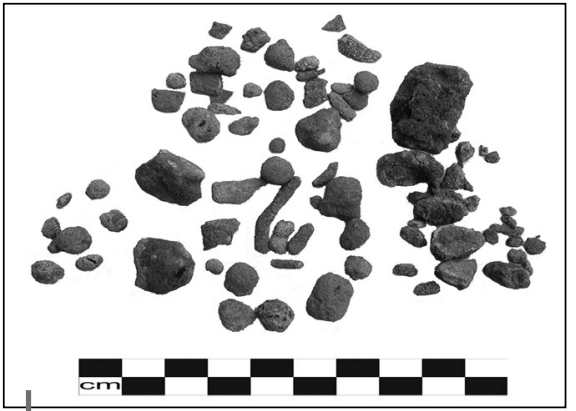

Figura 10 - Prills o gotas de cobre producto del recalentamiento del mismo

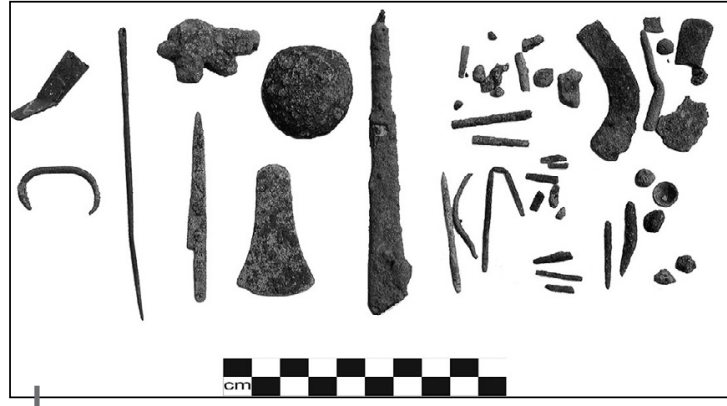

Figura 11 - Formas metálicas en proceso de manufactura y con defectos de fabricación registradas en el taller orfebre

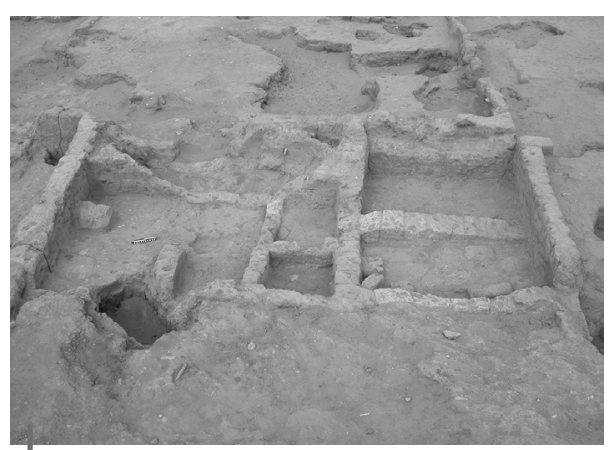

Figura 12 - Ambientes 27-25a, 27-25b, 27-27, 27-28 y 27-29. Pequeñas estructuras que posiblemente funcionaron como depósitos asociados a la producción de metales

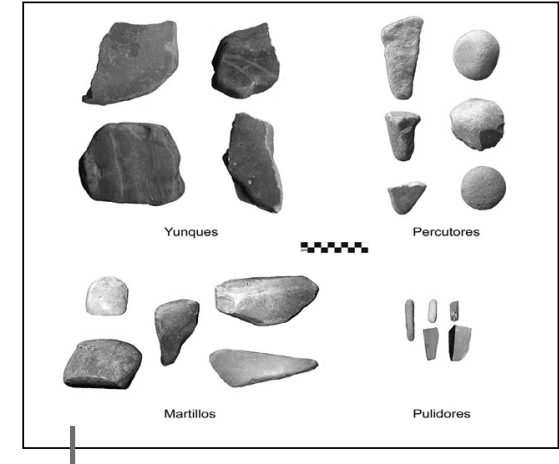

Figura 13 - Material lítico asociado a actividades relacionadas a la elaboración de piezas metálicas, registrados en el subconjunto 3 del Conjunto Arquitectónico 27

\section{1. El material recuperado}

Una vez finalizadas las excavaciones en el Conjunto Arquitectónico 27 se procedió a efectuar el análisis preliminar del material recuperado. Éste consistió en la limpieza e inventario de los elementos cerámicos, líticos y metálicos obtenidos en cada uno de los ambientes intervenidos. Los resultados, que a continuación presentamos, confirman nuestras sospechas acerca de la presencia de un taller metalúrgico en este conjunto, considerando las cifras estadísticas de presencia y acumulación de elementos metálicos y líticos relacionados con estas actividades, concentrados en los ambientes 27-30 (penúltima ocupación) y 27-15 (antepenúltima ocupación), así como su notable ausencia en los demás sectores del Bloque Arquitectónico (cuadros 1-5).

\section{2. Los metales}

La muestra de material metálico recuperada consta de 467 elementos, siendo el metal predominante el cobre $(\mathrm{Cu})$. Del total de dicha muestra, los más altos porcentajes provienen de los ambientes 27-15 y 27-30, precisamente aquellos relacionados con actividades de producción metalúrgica, con cifras de $37 \%$ y $27,2 \%$ respectivamente (cuadro 1). La muestra 
en su totalidad fue clasificada bajo un criterio morfológico siendo dividida en tres grupos: objetos e instrumentos, fragmentos y prills. En el primer grupo fueron considerados los elementos claramente reconocibles, en algunos casos se hallaron completos y en otros sólo algunos fragmentos. Como parte de este grupo se identificaron agujas, dardos, gancho, cuchillo, porras, objeto de forma zoomorfa y cuentas. Todos éstos constituyen el $6,2 \%$ del total de la muestra, predominando las agujas que abarcan el 4,1 \% de la misma. En el grupo fragmentos, se incluyeron los elementos que no fueron posibles de identificar, por lo que se los agrupó según sus formas generales en alargados, laminares, esféricos, alambres e indeterminados. A este grupo corresponde el $58 \%$ del total, predominando los fragmentos laminares con 20,6\% del total, seguidos de los indeterminados con 19,9\% y después los fragmentos alargados rectos con 13,7 \%. En el tercer grupo hemos incluido los llamados prills (Shimada, 1994; Topic, 1990) o gotas de cobre, las cuales son producto del recalentamiento de este metal. Estas gotas flotan sobre la escoria y al ser refundidas formarán lingotes de cobre (Shimada, 1994). A este grupo pertenece el 35,5\% del total de la muestra (cuadro 1).

A nivel de las 3 fases ocupacionales excavadas podemos observar que en el último nivel de ocupación sólo se obtuvieron 5 fragmentos que forman el 1,1\% de la muestra (cuadro 2). Asimismo, el material metalúrgico asociado a la penúltima ocupación proviene en su mayoría del Subconjunto 3. Gran parte de este material está asociado a los rellenos del ambiente 27-30, registrándose también material asociado a la remodelación del piso 2 de dicho ambiente. La forma predominante es el prill, con $71,1 \%$ del total de esta ocupación (cuadro 2). Finalmente tenemos que la mayor cantidad de elementos metálicos contextuales provienen de la antepenúltima ocupación, básicamente del Subconjunto 3, donde predominan los prills, los fragmentos indeterminados y los fragmentos alargados rectos (cuadro 2). De esta ocupación, el ambiente del cual se obtuvo el mayor porcentaje de material fue el 27-15, específicamente del relleno de su piso 2, el cual arrojó el 52,2 \% del total de la muestra asociada a esta ocupación (cuadro 3). Éste es seguido por el ambiente 27-25. El 56,3\% de la muestra de este ambiente se recuperó del relleno de la remodelación del piso 3, constando de fragmentos indeterminados, alargados y prills (cuadro 3).

\section{3. Los elementos líticos}

El total de la muestra lítica recuperada consta de 571 elementos, los que están comprendidos en 31 categorías donde predominan las cuentas con un 10,5\% del total de la muestra, seguido por los guijarros sin huellas de uso $(9,6 \%)$ y los percutores $(8,8 \%)$ (cuadro 4$)$. Lo que aquí queremos destacar es que el ambiente que presenta mayor número de objetos líticos en contexto es el 27-15 con un total de 81 piezas (14,2\%) comprendidas en 23 categorías. En este espacio predominan los guijarros sin huella de uso, los elementos pulidos en proceso y los yunques. De igual modo, el ambiente 27-30 presenta un total de 40 piezas que representa el $7 \%$. Estas piezas fueron agrupadas en 18 categorías en donde prevalecieron los percutores y los pulidores trabajados (cuadro 5).

\section{4. Discusión}

La lectura de los datos presentados nos conlleva a precisar y enfatizar ciertos aspectos del registro arqueológico. En primer lugar, la existencia de un centro de producción metalúrgica en el Bloque Arquitectónico 27-30, específicamente en la parte sur del Subconjunto 3 del Conjunto Arquitectónico 27, se sustenta en la presencia de elementos relacionados con estas actividades, entre ellos se cuenta con herramientas líticas, toberas de cerámica, restos de cerámica con cobre adherido, desechos de metal fundido, prills, restos de instrumentos metálicos y fragmentos con defectos de fabricación. En este punto debemos incidir en el hecho de encontrar todos estos 
La especialización del trabajo: teoría y arqueología. El caso de los orfebres Mochicas

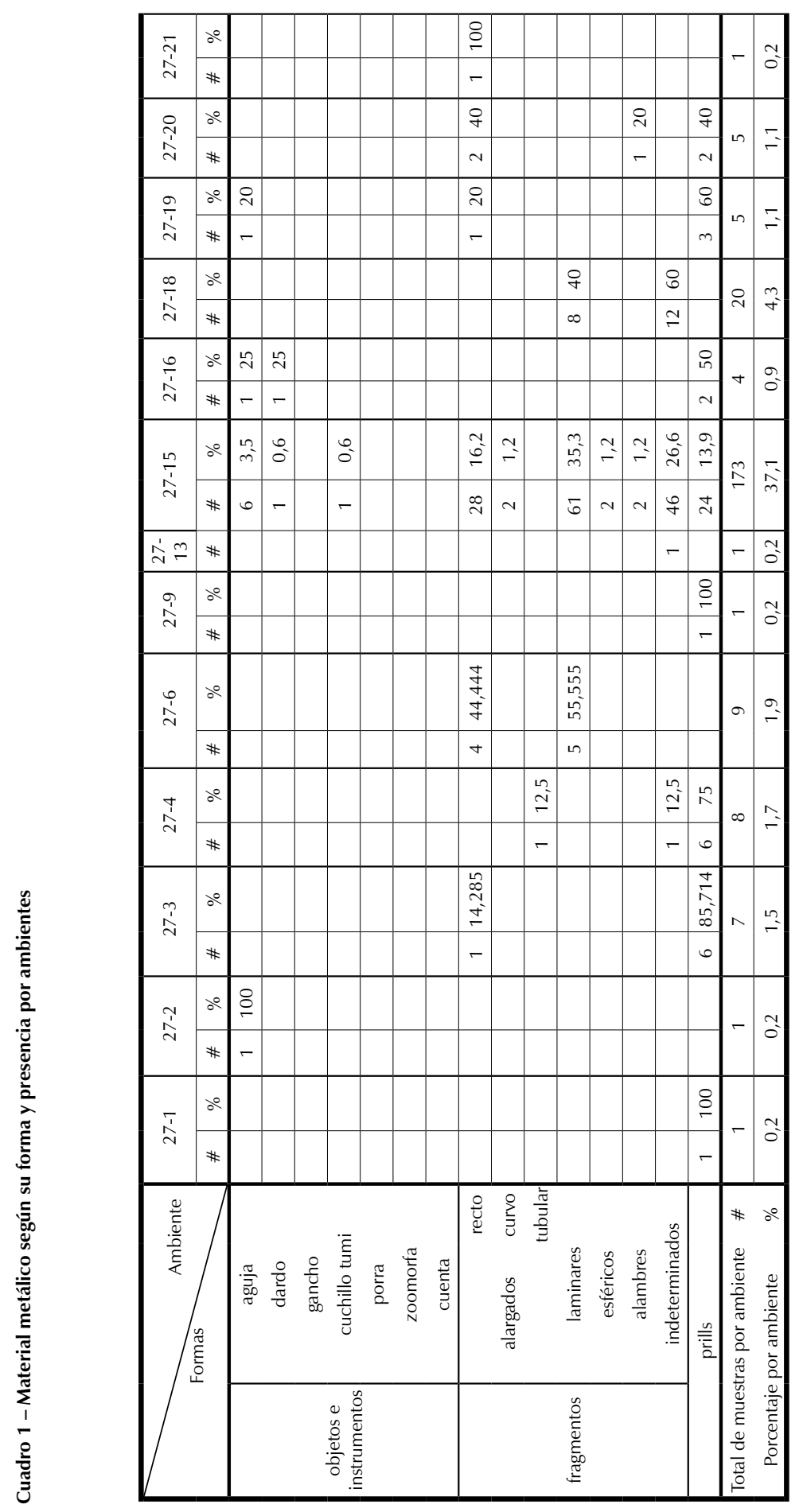


Santiago Uceda Castillo, Carlos E. Rengifo Chunga
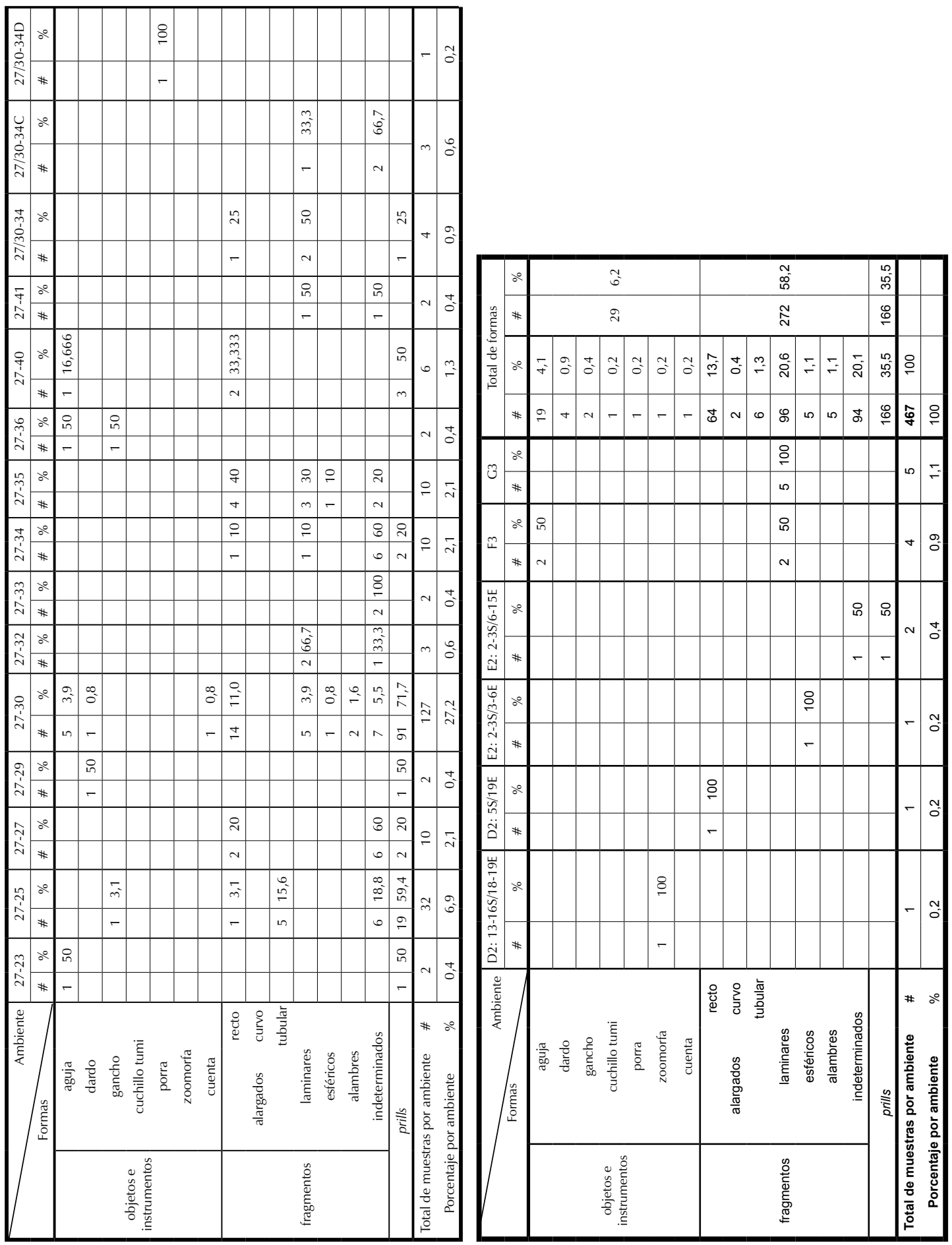
La especialización del trabajo: teoría y arqueología. El caso de los orfebres Mochicas

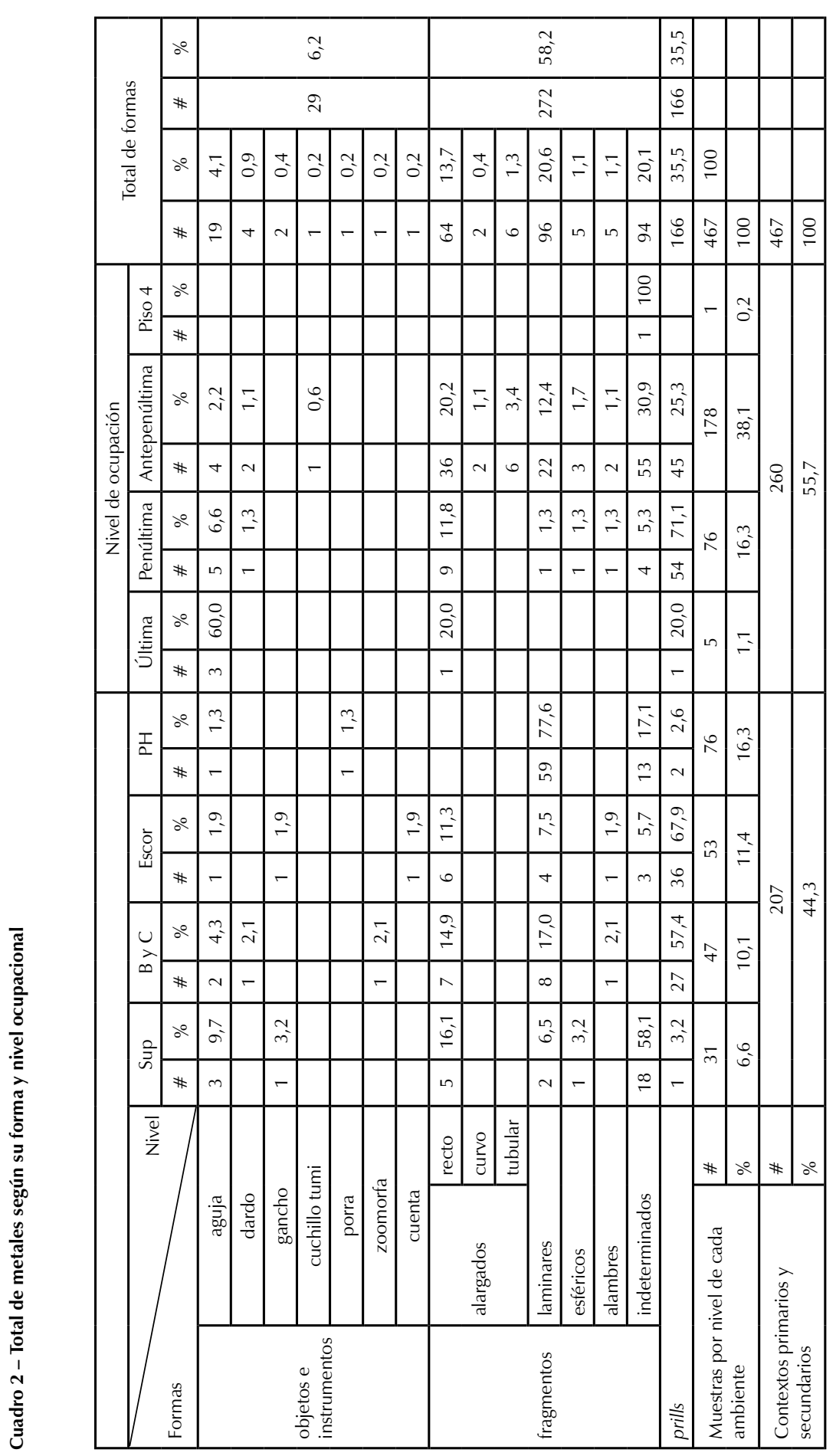


Santiago Uceda Castillo, Carlos E. Rengifo Chunga

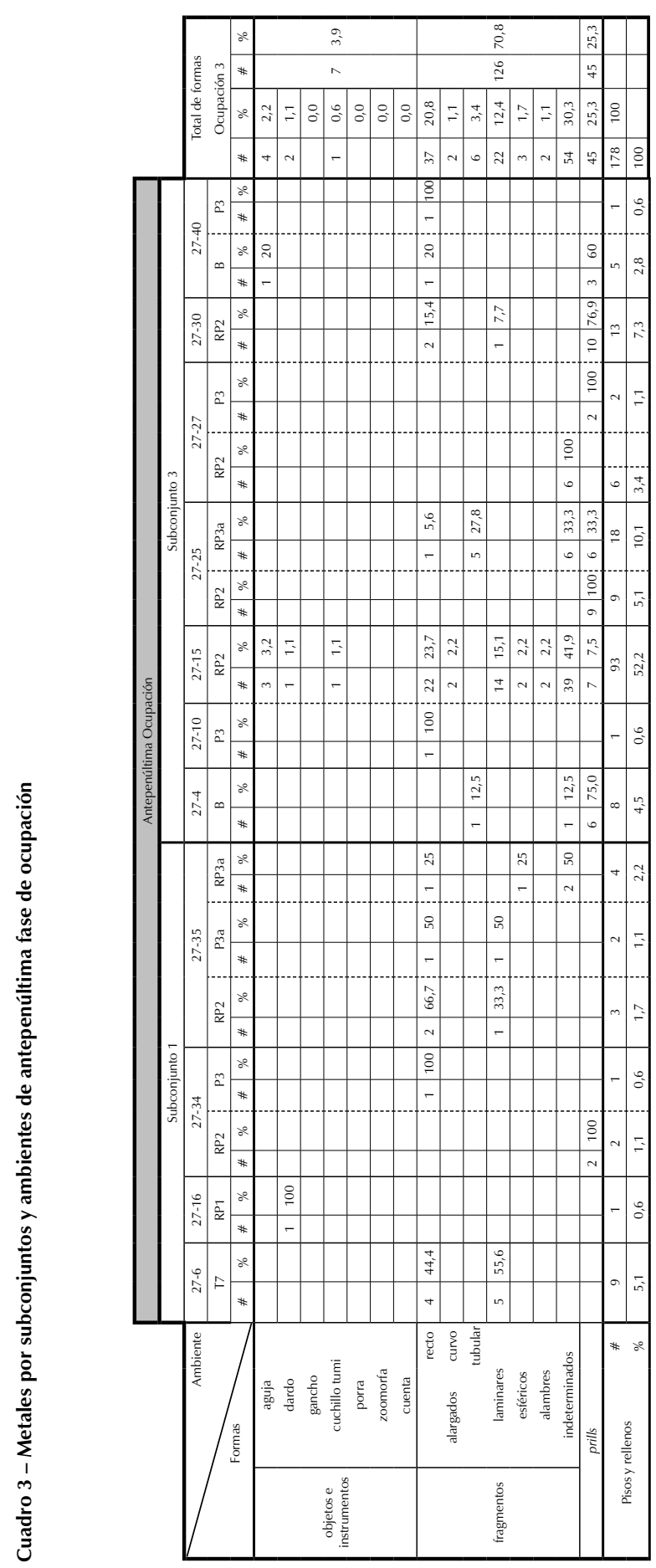




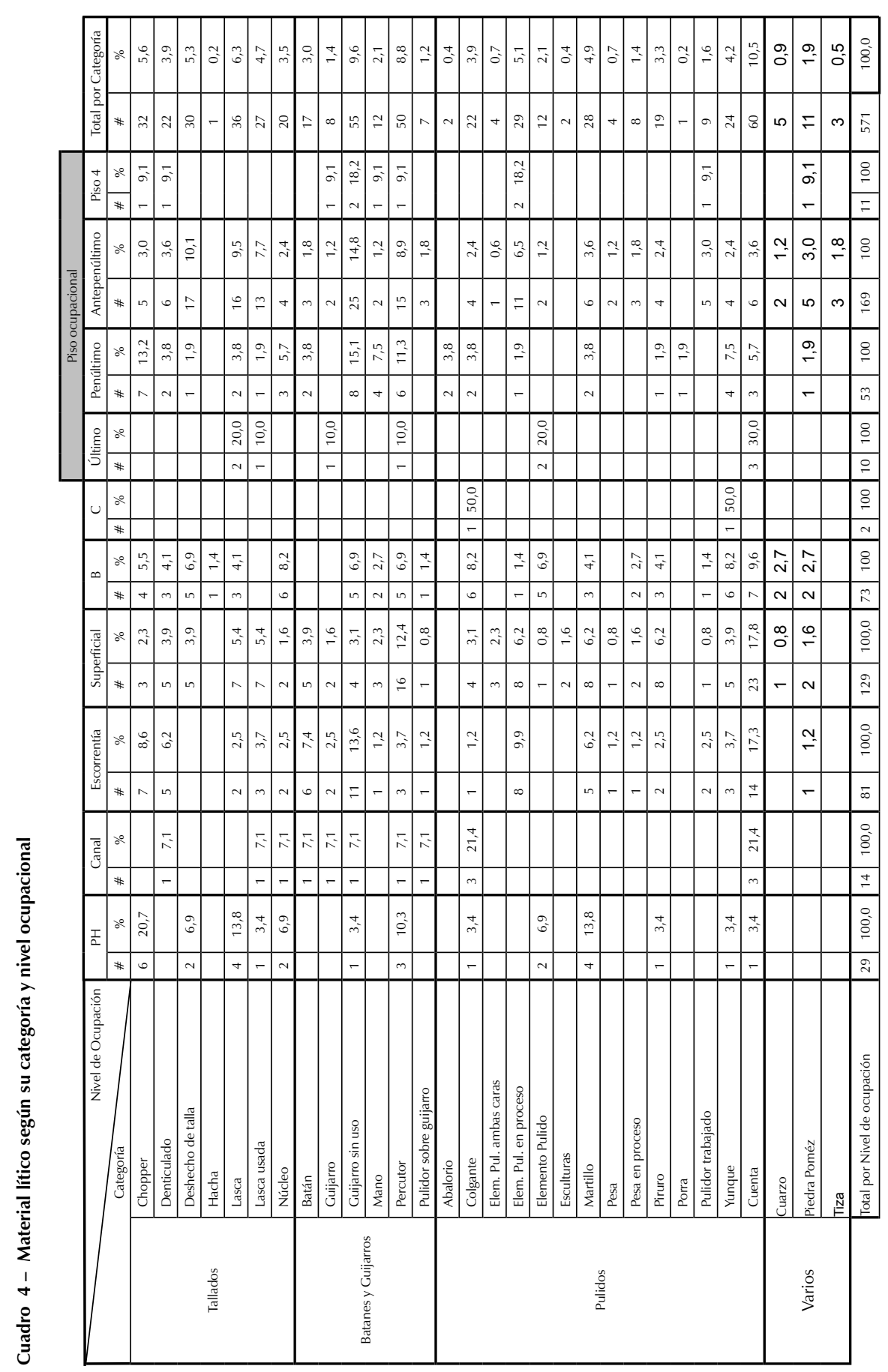




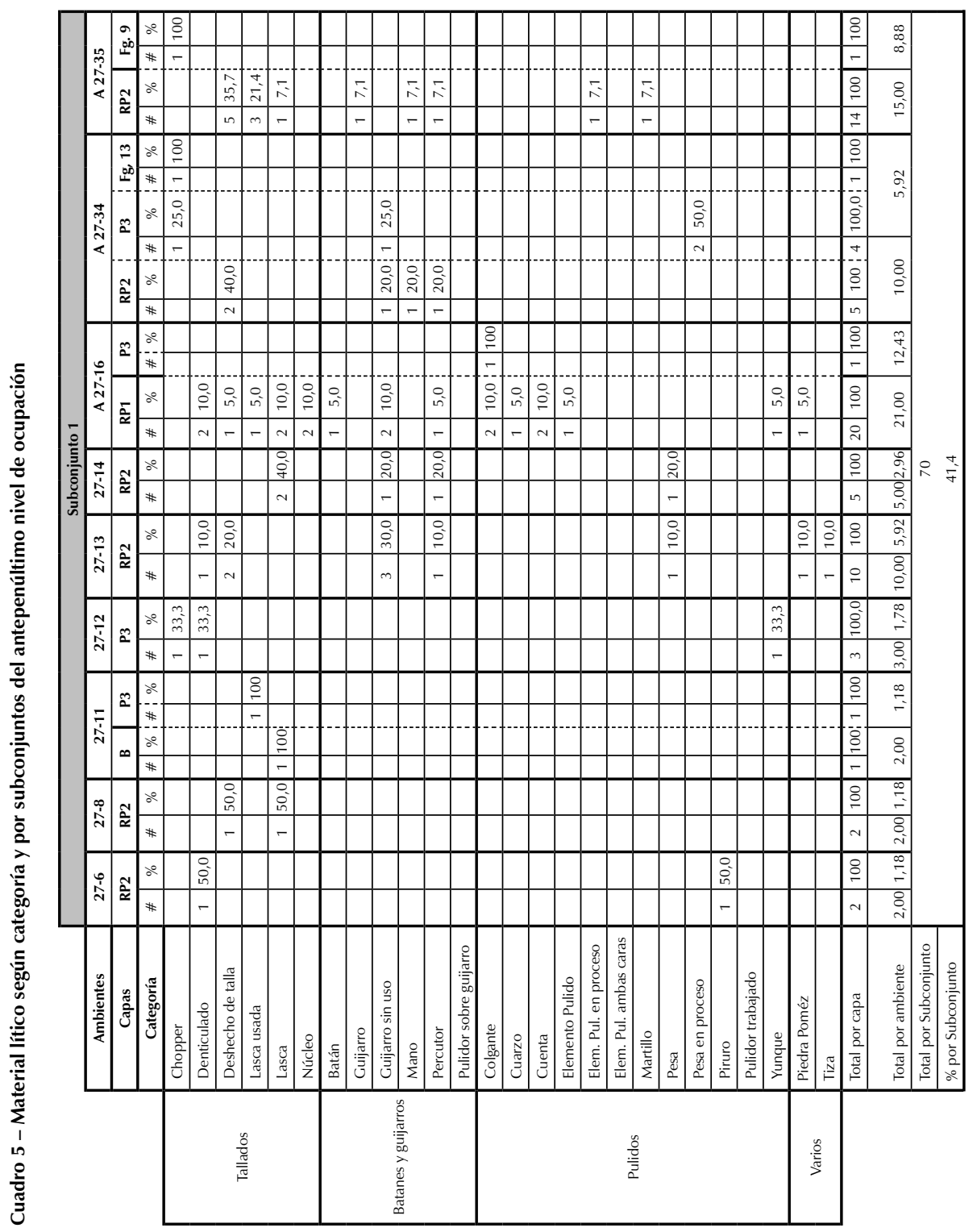




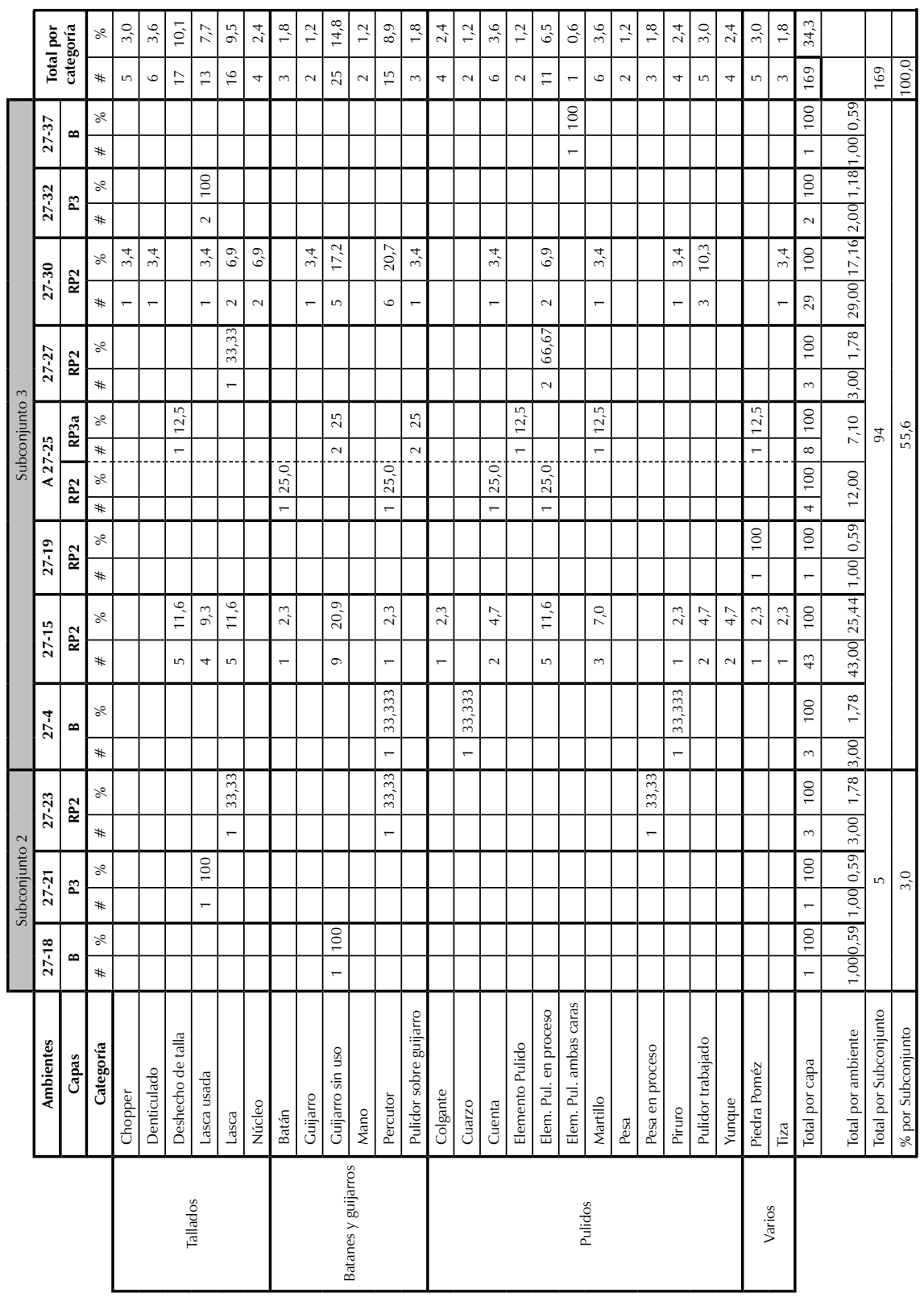


elementos ubicados dentro de un mismo espacio, y más aun si consideramos la ausencia de los mismos, tanto en cantidad como en calidad contextual, en los demás ambientes de Bloque Arquitectónico y en los demás conjuntos excavados.

Un segundo aspecto a discutir es la ubicación temporal de estos elementos en los distintos pisos ocupacionales y remodelaciones de este sector, hecho que exhibe de manera clara que se trata de una actividad realizada de manera continua a través del tiempo, lo que a su vez implica un constante proceso de especialización en estas labores. Al respecto hemos planteado que para el antepenúltimo nivel ocupacional el taller metalúrgico funcionó en el ambiente 27-15, ubicado al norte del ambiente 27-30. Si bien el pésimo estado de conservación de este sector no permitió recolectar una importante cantidad de material en contexto, la cantidad de material asociado con labores metalúrgicas proveniente del mismo, consistente en escoria de metal, prills, objetos defectuosos, cerámica con cobre adherido, toberas (figs. 14 y 15) y material lítico como martillos, pulidores y yunques, es clara evidencia de su relación con actividades de producción metalúrgica (figs. 16 y 17).

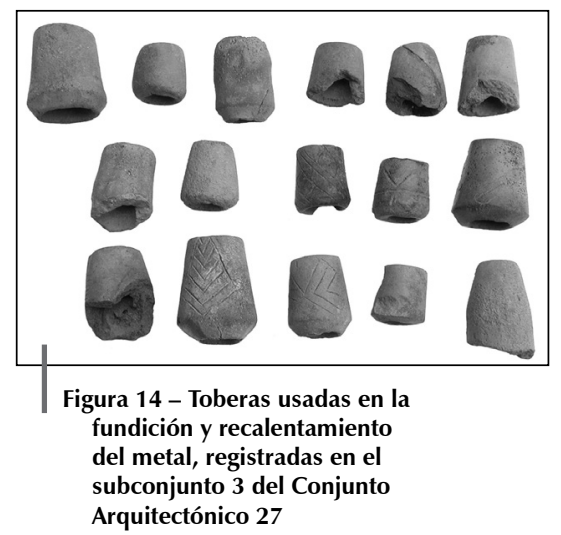

Arquitectónico 27

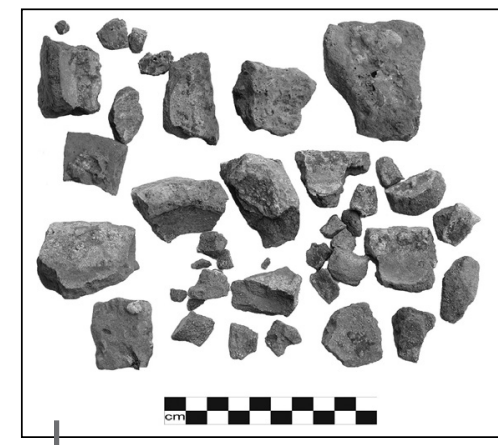

Figura 15 - Fragmentos de cerámica con cobre adherido. Posiblemente se traten de crisoles recuperados del taller orfebre

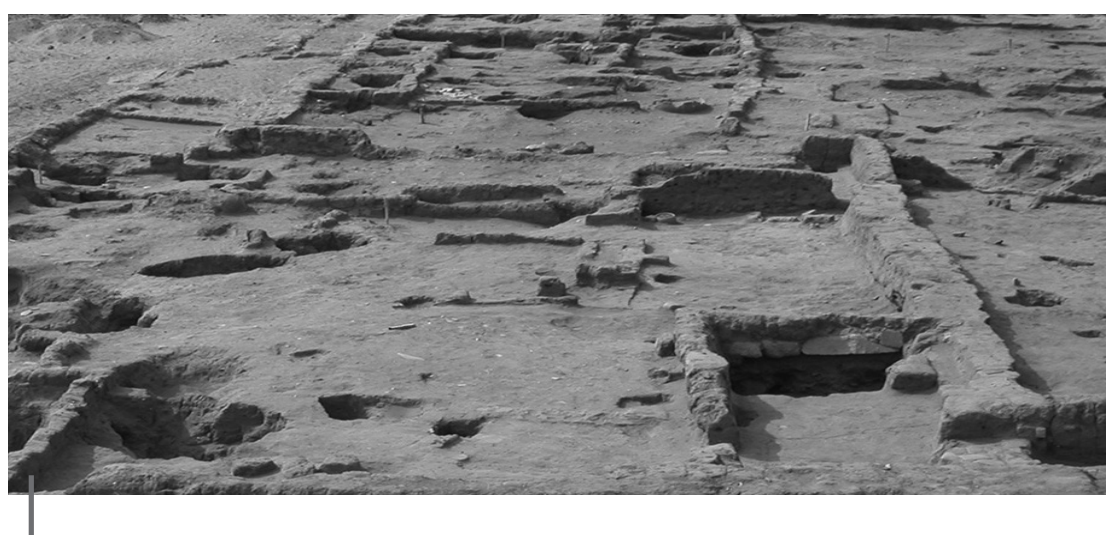

Figura 16 - Ambiente 27-15. Piso del antepenúltimo momento de ocupación, vista de oeste a este 


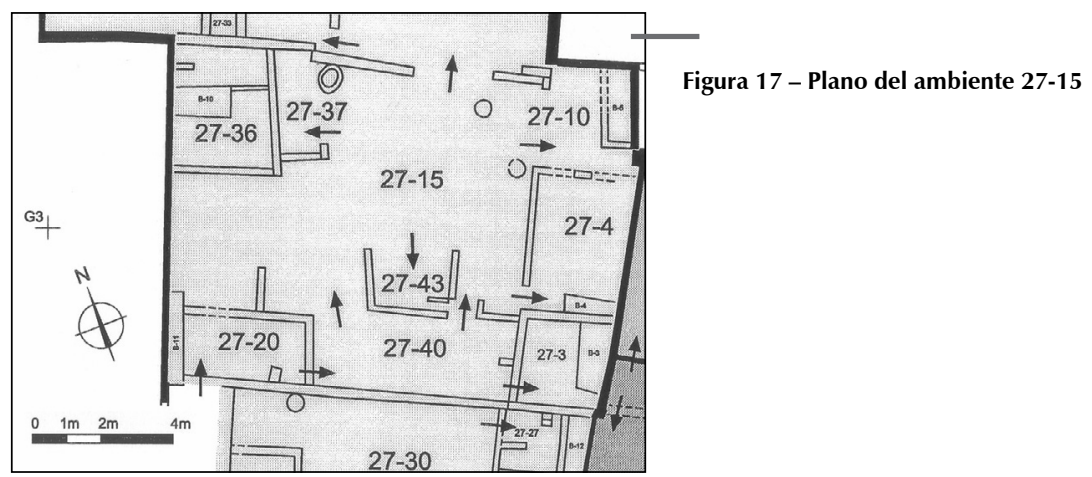

Como tercer punto queremos argumentar que la densidad de material de desecho registrado en este taller guarda una estrecha relación con la fase de la cadena operatoria de producción de objetos metálicos que aquí se ejecutó, que a nuestro entender se trataría de las labores de orfebrería. Al respecto queremos traer a colación dos aspectos del registro presentado, por un lado la ausencia de grandes cantidades de escoria, y por otro lado la no muy abundante cantidad de objetos de metal. Con referencia al primer punto es plausible pensar que los desechos metálicos pueden haber sido reutilizados, es decir, los volvieron a fundir. Considerando su rareza, esta forma de reutilización ha sido casi una norma en las sociedades metalúrgicas. Asimismo, para las labores orfebres la cantidad necesaria de material para fundir es mínima comparado con la actividad de fundición propiamente dicha. Finalmente, respecto al segundo punto, la ausencia de objetos terminados se explica en el simple hecho que ellos deben estar en su lugar de destino, es decir las tumbas, los templos, formando parte de atuendos, o en las mismas residencias. Un buen ejemplo son las piezas de cobre dorado y oro encontradas en el templo Huaca de la Luna (Morales, 2004). Por ello no debe extrañarnos el que en este taller sólo se hallaran restos de objetos con defectos en su fabricación, los que seguramente serían luego refundidos.

Como sinopsis de estas argumentaciones podemos establecer, a la luz de los múltiples datos presentados, que se trata de un taller metalúrgico especializado en labores orfebres, las cuales estuvieron dirigidas y ejecutadas por individuos especialistas que desarrollaron sus actividades en un espacio arquitectónico diseñado para tal fin. En este aspecto coinciden muchos de los investigadores de esta sociedad, aceptando la alta especialización artesanal existente (Alva, 2004; Bawden, 1996; Donnan, 2003; Shimada, 2001; Uceda, ms). Cabe enfatizar, además, que la orfebrería Mochica difícilmente estuvo dirigida por simples artesanos (Bernier, 2005). La alta calidad de manufactura de las piezas conocidas refleja un complejo conocimiento de las propiedades de cada uno de los metales trabajados, así como las reacciones de los mismos ante los distintos tratamientos a los que fueron sometidos. Ello exige un proceso de aprendizaje generación tras generación, lo cual obviamente conlleva a la especialización de una actividad. Los espacios que ellos utilizaron estuvieron arquitectónicamente bien definidos y fueron usados durante largos periodos. La densidad de material recuperado es mucho más amplia que la que el simple núcleo familiar requiere, como sería el caso de simples artesanos. Finalmente, el contexto general de este centro urbano Mochica indica que esta sociedad ya había alcanzado un alto nivel de complejidad social.

Recientes estudios metalúrgicos de objetos Mochicas en Huaca de la Luna, San José de Moro y Sipán vienen ofreciendo resultados que muestran el alto nivel tecnológico alcanzado por estos artesanos, lo cual reafirma que los orfebres Mochicas alcanzaron sin ninguna duda un nivel de especialistas (Fraresso, comunicación personal 2006). 


\section{LA IDEOLOGÍA EN LA PRODUCCIÓN ORFEBRE DE HUACAS DE MOCHE}

En un grupo social fuertemente estratificado, con una marcada pirámide jerárquica y donde los roles sociales justificaban la mayor o menor capacidad de acceso a bienes y recursos, la presencia de especialistas nos lleva a indagar acerca de las relaciones que ellos mantuvieron con las clases dominantes, así como con la gente del común y entre ellos mismos. Asumimos, dada la trascendencia de su función, que debió existir una cercana relación entre dichos especialistas y las esferas de poder Mochica, ya que fueron ellos quienes debieron fabricar y/o dirigir los procesos de producción y manufactura de una serie de objetos que simbolizaron, legitimaron y materializaron el poder por parte de quien los manipulaba, en este caso la élite gobernante.

Dentro de la escala jerárquica Mochica, podemos ubicar a los especialistas como una clase social intermedia entre gobernantes y gobernados, al interior de la cual es posible inferir que existieron distintos y muy complejos niveles de status dada la amplia gamma de productores y la distinta demanda que tenía cada uno de ellos. Esta idea acerca de la posición social intermedia de los especialistas se ve sustentada por 2 tipos de contextos: las estructuras de los Bloques Arquitectónicos y el hallazgo de 2 tumbas de alfareros que contenían un rico ajuar funerario conformado por piezas de cerámica de alta calidad, muy semejantes a aquellas recuperadas en los contextos del templo Huaca de la Luna (Uceda \& Armas, 1998).

Dentro de la propuesta de que los bloques arquitectónicos funcionarían como espacios urbanos restringidos a grupos corporativos diferentes (Uceda, ms), se arguye que cada uno de ellos fue liderado y gobernado por un miembro de la élite Mochica, quien tuvo a cargo la administración de las actividades económicas específicas que se desarrollaron en cada bloque constructivo. En este sentido, cada especialista que trabajaba dentro de un respectivo conjunto residencial debió estar adscrito al jefe o señor de dicha residencia, lo cual le otorgaba un status mayor al de los campesinos u otros miembros de la sociedad Mochica. Sería en este contexto que sus productos circularon y se distribuyeron a través de la red que los grupos corporativos establecían dentro del centro urbano y muy posiblemente fuera de él, hecho que además les otorgaba un cierto grado de independencia para la fabricación y posterior comercio de productos utilitarios que tenían una carga simbólica menor, situación que retomaremos más adelante.

Por otra parte, también hemos argumentado que el status de los artesanos Mochicas podría estar en clara correspondencia con el significado y la relevancia otorgada al material producido por parte de sus consumidores (Rengifo \& Rojas, 2005; ms). De este modo podemos sostener que las piezas metálicas, por estar íntimamente ligadas a la parafernalia litúrgica y ceremonial que utilizaba la élite Mochica, adquirían la importancia y relevancia que tenían los ceremoniales dentro de esta sociedad. Por ello, es claro en el registro arqueológico que estos materiales están siempre asociados a miembros de la élite, pues, a través de ellos, la sociedad reconocía el rol e importancia de los individuos que los ostentaban (véase las tumbas de Sipán, San José de Moro, Dos Cabezas, El Brujo, etc.).

En el sitio Huacas de Moche, durante el periodo Moche IV, la fabricación a gran escala de objetos suntuarios puede explicarse a partir de la creciente demanda de éstos por parte de los grupos de poder y de la población urbana. Creemos que las relaciones sostenidas por los productores, tanto con el grupo consumidor como entre ellos mismos, pueden discernirse a partir del tipo de objetos fabricados. Así tenemos: objetos ligados a rituales y ceremonias; objetos personales, cuyo valor puede variar dependiendo de si son indicadores de status y poder o simples adornos indiferenciados; y finalmente objetos que son instrumentos de producción para otras actividades.

Bajo esta perspectiva es posible examinar la producción metalúrgica como una actividad condicionada por factores económicos, políticos e ideológicos, lo cual habría generado distintos tipos de relaciones entre los productores metalurgos y los consumidores, donde entraron en juego factores de demanda, restricción y negociación, hecho que en mucho de los casos habría favorecido los intereses de estos especialistas. 
Es indudable que los objetos de metal de carácter suntuario deben haber sido uno de los bienes más preciados y cotizados de la época en cuestión. Su complejo proceso de manufactura y producción debió requerir la participación de mano de obra calificada y lo más probablemente es que también hubiese sido bien remunerada. En este contexto, la producción de objetos de metal debe haberse dado en condiciones muy particulares, dado el especial interés de los grupos dominantes por restringir el acceso a los mismos. Un peculiar ceramio descrito por Donnan $(1973 ; 1998)$ demuestra la gran trascendencia que tenía esta actividad artesanal, dado que fue una de las pocas en ser representada en la iconografía Mochica.

Las evidencias de producción metalúrgica en el Moche Viejo también nos permiten inferir el alto status del que gozaban los personajes involucrados en estas actividades. Así tenemos que el taller orfebre del Conjunto Arquitectónico 27 forma parte de la residencia de élite más grande excavada en el núcleo urbano: el Bloque Arquitectónico 27-30. Esta vivienda gozaba de una

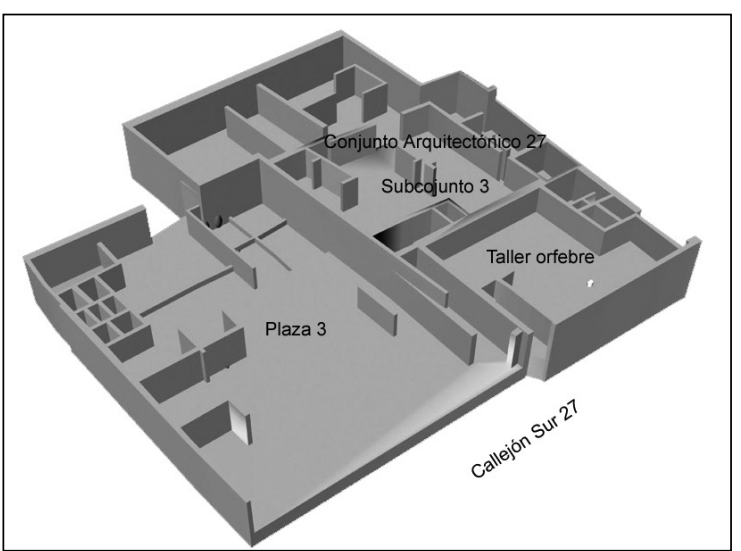

Figua 18 - Reconstrucción isométrica de la Plaza 3 y el Subconjunto 3 del Conjunto Arquitectónico 27 ubicación preferencial al estar muy cerca del templo religioso Huaca de la Luna y a las principales vías de circulación de la ciudad (la Avenida $\mathrm{n}^{\circ} 1$, los callejones Sur 27 y Norte 30), a una de las plazas públicas (Plaza 3) y cercana a otros centros de producción artesanal (el taller de abalorios del Conjunto Arquitectónico 12, el horno de fundición del Conjunto Arquitectónico 7 y un probable taller textil en el Conjunto Arquitectónico 9) (fig. 18).

Por otra parte es posible ilustrar un contexto social donde la fuerte carga simbólica contenida en los objetos de metal y su importancia en la legitimación del uso del poder generara que los grupos dominantes busquen restringir el acceso a dichos elementos, creándose así una serie de condicionantes ideológicos ligados a la producción metalúrgica, situación que debieron experimentar los residentes del Bloque Arquitectónico 27-30 en épocas Moche IV. Este vínculo mantenido entre la ideología y la producción especializada ha sido señalado por Costin (1991: 12) como un instrumento de las élites para controlar una ideología de poder. Asimismo, DeMarrais, Castillo y Earle han argumentado que una ideología de dominación puede ser sostenida a través de su materialización, es decir, dándole una forma física y concreta. La materialización hace posible extender una ideología más allá de los grupos locales y comunica el poder de una autoridad central a lo largo de un extenso territorio (DeMarrais et al., 1996: 16).

Baines \& Yoffee (1998: 235) usan el término de «alta cultura» para referirse a la producción y consumo de artículos estéticos, incluyendo objetos materiales y prácticas ceremoniales, bajo el control y para el beneficio de una élite interna. Inomata (2001) enriquece este concepto agregando nociones de un corte más abstracto, como el conocimiento estético y esotérico, argumentando que ellas subyacen a los objetos y prácticas ceremoniales además de servir para distinguir a las élites del común de la población. En este sentido, y de acuerdo con Baines y Yoffee, la «alta cultura» es decisiva en el proceso mediante el cual una élite controla los símbolos ideológicos y sus significados, por lo tanto es esencial en el desarrollo y mantenimiento de las élites y las civilizaciones.

A partir de estas premisas podemos llegar a definir el papel que cumplen los objetos artesanales en el proceso de controlar y sostener ideologías. La producción artesanal sería un paso necesario y un medio para conseguir los objetivos de un sistema ideológico. Más aun, coincidimos con Inomata (2001) cuando señala que los objetos artesanales no solo pueden ayudar a sostener 
y comunicar ciertos elementos de las ideologías, sino que, además, la producción artesanal por sí misma suele estar fuertemente cargada con significados y connotaciones ideológicas. Con respecto a ello Helms (1993: 53) sostiene que en muchas sociedades tradicionales la artesanía es considerada mucho más que el dominio de una técnica de manufactura y que los artesanos están asociados con poderes mágicos o supernaturales. En tales casos, los procesos de producción pueden implicar complejos rituales y el conocimiento necesario para la producción artesanal puede no estar limitado al campo de los materiales y las técnicas, sino que puede incluir componentes religiosos, históricos y de cosmovisión.

De este modo el conocimiento viene a ser un importante elemento de la producción especializada ya que permite a los productores y consumidores de objetos artesanales codificar y descifrar los mensajes políticos e ideológicos contenidos en ellos. Esto significa que el proceso de interpretación de los mensajes transmitidos en las actividades ceremoniales a través de la presencia o ausencia de determinados objetos artesanales es altamente complejo. Por un lado, diferentes individuos o grupos pueden interpretar determinada situación de diferente manera, limitando la efectividad del artesano y su producto como transmisor de una ideología, mientras por otro lado, la habilidad de interpretar y apreciarlos adecuadamente puede además llegar a ser parte de la «alta cultura» de Baines y Yoffee, constituyendo lo que Bourdieu llama el «capital cultural y simbólico». (Bourdieu, 1991: 229) El capital cultural es el conocimiento que permite, a quien lo posee, entender y apreciar ciertos tipos de relaciones y productos culturales; «una obra de arte tiene significado e interés sólo para alguien que posee la capacidad cultural, esto es, el código o cifrado, dentro del cual está codificado» (Bourdieu, 1984: 2). En muchas sociedades, el capital cultural está cercanamente vinculado con el capital y prestigio simbólico, el honor y la reputación. Al igual que el capital económico, los capitales cultural y simbólico están distribuidos desigualmente entre las clases sociales y bajo ciertas circunstancias el capital simbólico puede ser convertido en una posición política (Bourdieu, 1984: 291). La desigualdad del capital cultural y simbólico no está limitada a la división entre la élite y la no-élite; varias élites poseen diferentes tipos de capital cultural y simbólico y éstos juegan un rol decisivo en las relaciones de poder y competencia entre las élites mismas.

Si aceptamos que los especialistas, en este caso los orfebres Mochicas, jugaron un papel relevante en la materialización de los símbolos de poder (Bawden, 1996), entonces, es plausible pensar que su actividad favorecía a la construcción y mantenimiento de la «alta cultura» de Baines y Yoffee. En el valle de Moche, al menos durante los siglos VI y VII, existió un estado que había logrado imponer de manera contundente su ideología como recurso efectivo para obtener los favores divinos. Este panorama es claro en el registro arqueológico de Huacas de Moche e incluso en el vecino valle de Chicama (Uceda \& Tufinio, 2003; Uceda, 2004). Esta ideología, aceptada por sanción divina, fue materializada en forma de templos y objetos suntuarios que exhiben símbolos iconográficos y personajes mitológicos que llegaron a formar parte de lo que, parafraseando a Baines y Yoffee, podríamos llamar la «alta cultura Mochica», donde el «capital cultural y simbólico» de Bourdieu era restringido a los grupos de clase alta y a algunos de clase media.

En este punto cabe preguntarse acerca de la naturaleza y carácter de la especialización artesanal Mochica, dado que al aceptar su participación y conocimiento de los aspectos ideológicos de esta sociedad asumimos que su actividad debe haber estado regida por normas estructuradas y sancionadas en el subconsciente social. En este sentido podemos traer a colación la distinción planteada por Brumfiel \& Earle (1987) entre la especialización independiente y la especialización adjunta. De acuerdo a estos investigadores, la especialización independiente implica la producción de objetos para una demanda no específica y sus actividades de producción son guiadas por principios de eficiencia y rendimiento. Por otra parte la especialización adjunta es la producción de objetos para las élites o instituciones gubernamentales por especialistas cuyo campo de acción estaba contractualmente limitado por sus patrocinadores. Así la especialización independiente se desarrolla en respuesta a la diversidad de recursos y al crecimiento de la densidad poblacional, donde el óptimo rendimiento y la eficiencia son los factores clave en 
su desarrollo, mientras que la especialización adjunta surge del explícito deseo de las élites gobernantes de controlar ciertos bienes políticamente trascendentes.

Al respecto, en esta oportunidad queremos llamar la atención sobre un término que Inomata (2001) propone como alternativa al esquema de Brumfiel y Earle: embedded specialization (que podemos traducir como especialización adscrita o especialización por adscripción). Los especialistas adscritos actúan como parte integral de un hogar o economía local, donde su trabajo no es definido en términos económicos o de clases sino en términos de producción familiar, lo que implica que para los artesanos la noción de afiliación de grupo estaba por sobre otros aspectos del status adquirido.

Examinando el caso de los artesanos de Huacas de Moche, encontramos apreciaciones como las de Bawden (1996) y Morales (2003), quienes concuerdan en señalar que las habilidades de los artesanos Mochicas sirvieron directamente a los intereses de poder de la élite. Morales incluso es más enfático al señalar que los arquitectos y los muralistas elaboraron las obras arquitectoiconográficas de los templos como parte de una actividad programada por una élite gobernante, es decir, el artista Mochica no habría tenido libertad para crear.

«No hubo licencia para la inspiración individual, pues los códigos fueron creados, impuestos y manejados por las castas dominantes: ellos la diseñaron, la impusieron y modificaron para el manejo exclusivo de las élites». (Morales, 2003: 435)

Sin embargo, creemos que las circunstancias que vivieron los especialistas debieron ser menos estables y mucho más dinámicas, es decir, que en determinados momentos también pudieron actuar con cierta independencia, haciendo uso de su poder y prestigio sociopolítico.

La idea de considerar a algunos artesanos Mochicas dentro de la categoría de adscripción familiar podría tener un sustento empírico a partir de las 2 tumbas registradas en el taller de alfareros (Uceda \& Armas, 1997; 1998). Se trata de 2 contextos funerarios correspondientes a dos ocupaciones distintas y consecutivas, que indica que se trata de dos individuos de generaciones distintas y que probablemente tuvieron vínculos filiales entre sí. De comprobarse que estos personajes nacieron en el seno de una familia de ceramistas, entonces, habrían adquirido, a partir de ese momento, el grado de especialistas, y por lo tanto así se explicaría que la alfarería fue la principal función que desarrollaron durante su vida. Claro está que se trata de una inferencia bastante hipotética y que deberá ser comprobada mediante métodos analíticos de ADN, sin embargo sirve para exponer a la especialización adscrita como una alternativa que complemente y concilie los rígidos términos de especialización independiente y especialización adjunta.

Situación similar pudo haberse dado con los metalurgos, en este sentido podemos citar el caso de los 7 entierros excavados en el área de trabajo de metal del Sector I de Batán Grande (Shimada et al., 1982), donde dichas tumbas contenían numerosas ofrendas funerarias de cerámica y metal de alta calidad. Los investigadores del sitio suponen a partir de estos datos que la gente enterrada en el centro operacional del forjado del metal fueron herreros que pudieron haber gozado de un status superior al de los demás operarios de la cadena productiva de objetos metálicos (Shimada et al., 1982).

Aquí llegamos a un punto donde habría que preguntarse si realmente estos artesanos dependían totalmente de un jefe miembro de la élite. Creemos que el contexto arquitectónico que hemos presentado es una prueba que apoya la premisa que los especialistas en general y los metalurgos en particular estuvieron sujetos a un miembro de la élite Mochica. Además, estos datos nos ilustran un panorama donde podemos asumir que los orfebres de Huacas de Moche estuvieron constantemente involucrados con una red de comercio, transacciones e intercambios a nivel de las clases más altas del valle, desempeñando uno de los papeles principales dadas las implicancias ideológicas que envolvían su producción. Es así que en las representaciones iconográficas de los más importantes ceremoniales y rituales Mochicas se puede observar a los personajes principales ataviados con una vistosa parafernalia compuesta en muchos casos por elementos de metal (tocados, narigueras, penachos, pecheras, brazaletes, cetros, etc.). Por otra parte también es conocido que las tumbas de los personajes más importantes de la sociedad Mochica contienen una importante cantidad de objetos de metal finamente trabajado (Alva, 
2004; Donnan \& Castillo, 1994; Donnan, 2003; Franco, 2006). Estas apreciaciones sustentan la trascendente función que debieron cumplir los especialistas metalurgos en la construcción de la identidad de los personajes de la élite Mochica tanto en la vida como en la muerte, por lo tanto se trata de personas que gozaban del favor divino y del prestigio social que legitimaba su alto status y cercanía a las esferas de poder.

No obstante, al margen de esta discusión, creemos que los especialistas Mochicas formaron parte de un nutrido y complejo grupo social que tenía acceso a un conocimiento privilegiado, debemos remarcar, además, que esta clase social puede presentar muchas gamas y variantes de status, privilegios e influencia social. Incluso en los orfebres mismos podrían abrirse las posibilidades de que o bien existieron dos segmentos divididos entre aquellos encargados exclusivamente de la elaboración de la parafernalia ritual de los más altos dignatarios (por ejemplo el orfebre o los orfebres que elaboraron el manto ceremonial felínico de los chacchadores de coca hallado en la Huaca de la Luna [Uceda, 2004], o los atuendos con que debieron haber sido enterrados los grandes señores de este templo, que debido al intenso saqueo al que fue sometido poco o nada quedó para el registro arqueológico) y aquellos que estaban más involucrados con la clase que residía en el núcleo urbano (también fabricando elementos simbólicos y ornamentales pero a un nivel jerárquico menor que los primeros), o la posibilidad de que un mismo grupo de orfebres que pudo abastecer a ambos niveles sociales. La presencia de especialistas metalurgos en el Conjunto Arquitectónico 27 podría sustentar esta última opción, dadas las características de su ubicación y elementos contextuales que líneas arriba fueron expuestos.

De ser así, entonces podemos esbozar algunos de los rasgos productivos y las implicancias sociales de este taller. Por un lado tenemos que se trataría de un grupo de especialistas artesanos que fabricaron objetos de distintas calidades, negociando lo mejor de su producción con las altas élites dirigenciales, explicándose así el notable contraste que existe entre las piezas metálicas registradas en las tumbas del núcleo urbano con aquellas que conforman el ajuar funerario de los grandes señores que se enterraron en el área sacra. Ésto a su vez nos conlleva a pensar que posiblemente los más finos trabajos estuvieron a cargo de maestros artesanos, mientras que los demás eran ejecutados por aprendices. De otra parte, y en directa relación con lo anterior, se puede argumentar que estos orfebres tuvieron acceso a las materias primas necesarias para la elaboración de piezas de oro, cobre y estaño, lo que a su vez involucra el dominio de las técnicas de manufactura para trabajar dichos metales. Finalmente, y tal como hemos sugerido anteriormente, estos artesanos habrían estado involucrados también con el aprovisionamiento de instrumentos y artefactos tanto de uso doméstico como utilitario para otro tipo de labores productivas, sea en la fabricación de textiles, alfares, abalorios u otros, lo que supone la existencia de una red de intercambios a nivel de este asentamiento urbano que pudieron tener como centro de ejecución las plazas públicas (Rengifo \& Rojas, 2005).

Condiciones similares podemos encontrar en Pampa Grande, donde el taller orfebre registrado en la estructura 52 del Sector $\mathrm{H}$ se ubica adjunto a una serie de estructuras residenciales de élite (Shimada, 1994; 2001). Shimada (2001) sustenta que los restos de vasijas finas halladas en este taller reflejan la presencia personal de la élite supervisando los trabajos de los orfebres, es decir que las labores eran dirigidas por pocos especialistas y varios asistentes o aprendices (Shimada, 2001). Es claro además, que tanto éste como los demás talleres de producción registrados en Pampa Grande se hallan inmersos dentro de una compleja red urbana, donde a la vez funcionaron residencias, centros administrativos y templos religiosos.

Si avanzamos a épocas más tardías encontraremos un panorama similar en los especialistas que vivían en la capital del reino Chimú, Chan Chan (Topic, 1990) o en los entierros dedicados a artesanos durante el Horizonte Tardío en el cementerio Inca del sitio Rinconada Alta, valle bajo del Rímac (Guerrero in Carcedo \& Vetter, 2002). En ambos casos se hace referencia a los privilegios que se obtenía por pertenecer a esta clase productora.

Espinoza por su parte señala que durante el incanato casi todas las personas pertenecientes a las clases artesanales y mercantiles, por no poseer tierras de cultivo, se dedicaban por completo a su trabajo u oficio. 
«Se les reputaba de libres y no existía discriminación contra ellos. Podían movilizarse a voluntad; no mitaban ni hacían ayne ni mingas, pero pagaban sus impuestos». (Espinoza, 1987: 55)

El mismo autor considera que esta marcada división y especialización laboral explica el grado de perfección con que muchos pueblos llegaron a realizar sus obras artesanales, singularmente en cerámica, orfebrería, carpintería y textilería.

Otro aporte importante que hace Espinoza a partir de sus estudios acerca del contexto de las sociedades andinas durante los siglos XV y XVI, es con referencia a las condiciones de status de los productores. Aparentemente existían dos tipos de artesanos: los autónomos y los estatales. Los primeros trabajaban en sus propios talleres y tributaban manufacturando objetos con materia prima que les otorgaba el estado, lo restante lo vendían por su cuenta para conseguir sus artículos de consumo. Los segundos eran trasladados a lugares especiales señalados por el Inca, sin embargo, no pueden ser considerados como esclavos porque se le proveía de beneficios tales como tierras, pastos, regalos frecuentes, entre otros (Espinoza, 1987: 59). Del mismo modo, Rostworowski (2004: 327) hace mención de un documento del siglo XVI donde se otorga la encomienda de Chincha a Hernando Pizarro, en el escrito se afirma que los metalurgos de Chincha «sólo hacían su oficio y su tributo al Inca consistía en objetos manufacturados, pero podían también fabricar otros para sus propias granjerías».

Si bien se trata de épocas distintas, separadas por varios cientos de años y circunstancias disímiles, el hecho de que en todo momento los especialistas, especialmente los metalurgos, hayan gozado de un status preferencial es para tomar en consideración. Tales indicios que nos hacen presumir la posibilidad de que los artesanos orfebres Mochicas hubiesen vivido en un contexto similar al que se daría años después en el incanato, al menos en lo referente a su privilegiada posición como artífices directos de los símbolos de poder, riqueza y status social.

\section{COLOFÓN}

Los indicios de actividad artesanal especializada en el complejo Huacas de Moche son variados y contundentes, la presencia de talleres de producción especializada ubicados en los distintos sectores residenciales de este complejo arqueológico son prueba de ello. En esta ocasión nos hemos enfocado en el hallazgo de un taller de producción de objetos metálicos, es decir, se trata de la evidencia de gente especializada en labores orfebres viviendo y conviviendo con las más altas esferas sociales del valle de Moche durante los siglos VII y VIII aproximadamente. Estos vestigios nos ofrecen la posibilidad de explorar aspectos de orden tecnológico, productivo, sociopolítico e ideológico, en un contexto de creciente demanda de objetos suntuarios donde los especialistas desempeñaron un papel protagónico.

Con referencia a las cuestiones tecnológicas, podemos señalar que la evidencia de producción metalúrgica proveniente del sitio Huacas de Moche coincide en muchos aspectos con las versiones vertidas por los cronistas y con los datos arqueológicos obtenidos de otros yacimientos. Es posible sostener que, salvo algunas excepciones, las técnicas de manufactura, el instrumental y los procesos de producción de objetos de metal no variaron de manera sustantiva en aproximadamente 1500 años, contando desde el formativo hasta el incanato. Es probable que los procesos de extracción del metal en las minas o en los lechos de los ríos y el transporte a los lugares de fundición no variaran en su dinámica y cadena operatoria; en todo caso, los cambios se dieron en los modos de dirigir y controlar estas actividades, materializados en distintos mensajes simbólicos e iconográficos que probablemente estaban en directa relación con las tensiones y circunstancias sociales imperantes en cada época.

En el caso de los productores metalurgos, específicamente los orfebres del centro urbano Huacas de Moche, la preferencial ubicación de sus talleres y residencias, así como su privilegiado acceso a los recursos primarios y bienes de prestigio son claros indicadores del alto status que gozaban en relación a la población común del valle. La evidencia arqueológica aquí presentada expone 
a estos especialistas como uno de los más importantes y prestigiosos grupos de productores, dada la trascendencia de su participación en la elaboración de los principales elementos simbólicos de poder y status divino. En este sentido consideramos que su participación en la vida y desenvolvimiento de esta urbe debió ser más compleja de lo que suponemos. Por un lado podemos inferir una directa relación entre los orfebres y la construcción de la identidad social de los más importantes personajes de la élite Mochica, es decir, aquellos que la iconografía y la arqueología han identificado en las escenas ceremoniales representadas en los ceramios y en las lujosas tumbas que debido al intenso saqueo colonial no han sido posible registrar en el templo Huaca de la Luna, pero que sin embargo lo más probable es que sí hubiesen existido. De otro lado tenemos que dichos orfebres también estuvieron involucrados en la producción del material metálico registrado en el núcleo urbano, tanto en los contextos funerarios como en los rellenos y pisos de los espacios arquitectónicos, lo que supone un contexto de constantes relaciones comerciales y de intercambio a nivel de la clase urbana y con otros grupos especializados.

El taller orfebre del Conjunto Arquitectónico 27 nos ofrece clara evidencia que sustenta estas presunciones, pero además nos alcanza un caso en el cual la teoría de la especialización artesanal puede encontrar un punto de encuentro para las propuestas de especialización independiente, adjunta y adscrita. Es posible que en determinadas circunstancias y bajo un clima de estabilidad la adjunción a una élite de poder hubiese resultado beneficiosa para una familia artesana, mientras en momentos de fluctuación y caos, la independencia hubiera sido la mejor opción, contando además con el prestigio de tener adscrito el status de proceder de una casta de especialistas.

Finalmente, el contexto social en el que se dieron estas relaciones debió ser muy dinámico y quizás poco estable si asumimos las crecientes y constantes pugnas de las clases urbanas por obtener más poder y prestigio frente a ellas mismas. Asimismo, las elites dominantes debieron aplicar mecanismos que restringían el fácil acceso a los objetos suntuarios y por tanto a los códigos ideológicos que subyacen a éstos. En este sentido debieron entrar en constantes situaciones de negociación con dichos especialistas en busca de lograr circunstancias que favorezcan la estabilidad social y legitimidad del orden imperante.

\section{Referencias citadas}

ALVA, W., 1992 - Orfebrería del Formativo. In: Oro del Antiguo Perú: 17-116; Lima: Banco de Crédito del Perú. Colección Artes y Tesoros del Perú.

ALVA, W., 2004 - Sipán: Descubrimiento e Investigación, 259 p.; Lima, Perú.

ARMAS, J., 1999 - Talleres Alfareros Moche: secuencia y estructura espacial, Complejo Arqueológico Huacas del Sol y de la Luna. Proyecto de investigación para optar por el título de Licenciado en Arqueología. Escuela de arqueología, Facultad de Ciencias Sociales, Universidad Nacional de Trujillo.

BAINES, J. \& YOFFEE, N. 1998 - Order, legitimacy, and wealth in ancient Egypt and Mesopotamia. In: Archaic states (G. Feinman y J. Marcus, eds.): 199-260; Santa Fe: School of american Research Press.

BAWDEN, G., 1996 - The Moche, 375 p.; Oxford: Blackwell Publishers Ltd.

BENZONI de, G., 1967 [1565] - La historia del Mundo Nuevo; Caracas: Biblioteca de la Academia Nacional de la Historia, vol. 86.

BERNIER, H., 1999 - L'usage de la parure corporelle dans la cultura Moche du Pérou précolombien et le cas du site Moche, capitale Urbanie. Tesis de Maestría. Departamento de Antropología, Universidad de Montreal; Montreal.

BERNIER, H., 2005 - Étude archéologique de la production artisanale au site Huacas de Moche, côte nord du Pérou. Tesis doctoral. Departamento de Antropología. Facultad de Artes y Ciencas. Universidad de Montreal. 
BOURDIEU, P., 1984 - Distinction: A social critique of judgement of taste, 613 p.; Harvard University Press.

BOURDIEU, P., 1991 - Language and symbolic power (J. Thompson, ed.), 320 p.; Cambridge: Harvard University Press.

BOURGET, S., 2003 - Somos diferentes: Dinámica ocupacional del sitio Castillo de Huancaco, valle de Virú. In: Moche: hacia el final del milenio (S. Uceda \& E. Mujica, eds.): 245-267, T. I; Lima: Universidad Nacional de Trujillo y Pontificia Universidad Católica del Perú. Actas del Segundo Coloquio sobre la Cultura Moche (Trujillo, 1 al 7 de agosto de 1999).

BRUMFIEL, E. \& EARLE, T., 1987 - Specialization, Exchange, and Complex Societies: An Introduction. In: Specialization, Exchange, and Complex Societies (E. Brumfiel \& T. Earle, eds.): 1-9; Cambridge University Press.

CARCEDO, P., 1992 - Metalurgia Precolombina: Manufactura y Técnicas de Trabajo en la Orfebrería Sicán. In: Oro del Antiguo Perú: 265-305; Lima: Banco de Crédito del Perú. Colección Artes y Tesoros del Perú.

CARCEDO, P., 1999 - Instrumentos líticos y de metal utilizados en la manufactura de piezas metálicas conservadas en los museos. Boletín del Museo del Oro, N 44-45: 241-270; Bogotá: Museo del Oro-Banco de la República.

CARCEDO, P. \& VETTER, L., 2002 - Instrumentos utilizados para la fabricación de piezas de metal para el período Inca. Baessler-Archiv, Band 50: 47-66; Berlín: Beiträge zur Völkerkunde Museums für Völkerkunde Berlin.

CHAPDELAINE, C., 1998 - Excavaciones en la Zona Urbana de Moche durante 1996. In: Investigaciones en la Huaca de la Luna 1996 (S. Uceda, E. Mujica \& R. Morales, eds.): 85-115: Trujillo: Facultad de Ciencias Sociales de la Universidad Nacional de La Libertad-Trujillo.

CHAPDELAINE, C., 2001 - The Growing Power of a Moche Urban Class. In: Moche Art and Archaeology in Ancient Peru (J. Pillsbury, ed.): 69-87; Washington, D.C.: Studies in the History of Art 63. Center for Advanced Study in the Visual Arts, Symposium Papers XL, National Galery of Art.

CHAPDELAINE, C., 2003 - La ciudad de Moche: urbanismo y estado. In: Moche: hacia el final del milenio (S. Uceda \& E. Mujica, eds.): 247-285, T. II; Lima: Universidad Nacional de Trujillo y Pontificia Universidad Católica del Perú. Actas del Segundo Coloquio sobre la Cultura Moche (Trujillo, 1 al 7 de agosto de 1999).

CHAPDELAINE, C., BERNIER, H. \& PIMENTEL, V., 2000 - Investigaciones en el área urbana Moche. In: Investigaciones en la Huaca de la Luna 1999 (S. Uceda \& R. Morales eds.): 85-142; Trujillo: Facultad de Ciencias Sociales de la Universidad Nacional de Trujillo.

CHAPDELAINE, C., KENNEDY, G. \& UCEDA, S., 2001 - Neutron Activation Analysis of Metal Artifacts from the Moche Site, North Coast of Peru. Archaeometry, 43 (3): 373-391.

CHIGUAlA, J., GAMARRA, N., GAYOSO, H., PRIETO, G., RENGIFO, C. \& ROJAS, C., 2004 Dinámica ocupacional del Conjunto Arquitectónico 27 - Núcleo Urbano del Complejo Arqueológico Huacas del Sol y de la Luna. In: Proyecto Arqueológico Huaca de la Luna, Informe Técnico 2003 (S. Uceda \& R. Morales eds.): Trujillo: 83-152; Facultad de Ciencias Sociales de la Universidad Nacional de Trujillo.

CHIGUALA, J., ALMONACID, C., ORBEGOS, M., ROJAS, D. \& SANDOVAL, M. C., 2006 La integración funcional de los Conjuntos Arquitectónicos 17 y 35 como parte de un Bloque Arquitectónico en el Núcleo Urbano. In: Proyecto Arqueológico Huaca de la Luna. Informe Técnico 2005 (S. Uceda \& R. Morales eds.): 138-206; Trujillo: Facultad de Ciencias Sociales de la Universidad Nacional de Trujillo.

COSTIN, C. L., 1991 - Craft specialization: Issues in defining documenting, and explaning the organization of production. Archaeological Method and Theory, 3: 1-56.

DeMARAIS, E., CASTILLO, L. J. \& EARLE, T., 1996 - Ideology, materialization, and power strategies. Current Anthropology, 37 (1): 15-31; Wenner-Gren Foundation for Anthropological Research. 
DIEZ CANSECO, M., 1994 - La sabiduría de los orfebres. In: Vicús (K. Makowski, C. Donnan, I. Amaro Bullón, L. J. Castillo, M. Diez Canseco, O. Eléspuru Revoredo \& J. A. Murro Mena eds.): 183-209; Lima: Banco de Crédito del Perú. Colección Arte y Tesoros del Perú.

DONNAN, C. B., 1973 - A Precolumbian Smelter from Northern Peru. Archaeology, 26 (4): 289-297.

DONNAN, C. B., 1990 - An assesment of the validity of the Naylamp dynasty. In: The northern dynasties: kingship and statecraft in Chimor (M. Moseley \& Alana Cordy-Collins, eds.): 243-274; Washington, D.C.: Dumbarton Oaks Research Library and Collection.

DONNAN, C. B., 1995 - Moche funerary practice. In: Tombs for the living: Andean Mortuary Practices (T. D. Dillehay, ed.): 111-159; Washington, D.C.: Dumbarton Oaks Research Library and Collection.

DONNAN, C. B., 1998 - Un ceramio moche y la fundición prehispánica de metales. Boletín del Museo Chileno de Arte Precolombino, 7: 9-18; Santiago.

DONNAN, C. B., 2003 - Tumbas con entierros en miniatura: un nuevo tipo funerario Moche. In: Moche: hacia el final del milenio, T. I (S. Uceda \& E. Mujica, eds.): 43-78; Lima: Universidad Nacional de Trujillo y Pontificia Universidad Católica del Perú. Actas del Segundo Coloquio sobre la Cultura Moche (Trujillo, 1 al 7 de agosto de 1999).

DONNAN, C. B. \& CASTILLO, L. J. 1994 - Excavaciones de tumbas de sacerdotisas Moche en San José de Moro, Jequetepeque. In: Moche, propuestas y perspectivas (S. Uceda \& E. Mujica, eds.): 415-424; Lima: Universidad de La Libertad-Trujillo, Instituto Francés de Estudios Andinos, Asociación Peruana para el Fomento de las Ciencias Sociales. Actas del Primer Coloquio sobre la Cultura Moche (Trujillo, 12 al 16 de Abril de 1993).

DONNAN, C. B. \& MACKEY, C. J. ,1978 - Ancient Burial Patterns of the Moche Valley, Peru; Austin: University of Texas Press.

EPSTEIN, S. \& SHIMADA, I., 1984 - Metalurgia de Sicán: Una reconstrucción de la producción de la aleación de cobre en El Cerro los Cementerios, Perú. Beiträge zur Allgemeinen und Vergleichenden Archäeologie, 5: 379-430.

ESPINOZA SORIANO, W., 1987 - Artesanos, transacciones, monedas y formas de pago en el mundo andino: siglos 15 y 16. Tomo I, 213 p.; Lima: Banco Central de Reserva del Perú.

FRANCO, R., 2006 - Mystery Mummy. National Geographic Magazine, 209 (6): 70-83; Washington D. C.: National Geographic Society.

GAMARRA, N., GAYOSO, H., PRIETO, G., RENGIFO, C. \& ROJAS, C., 2004 - Dinámica ocupacional del Conjunto Arquitectónico 27 - Núcleo Urbano del Complejo Arqueológico Huacas del Sol y de la Luna; Trujillo: Escuela de arqueología, Facultad de Ciencias Sociales, Universidad Nacional de Trujillo. Informe de Prácticas Pre Profesionales.

GARCILASO DE LA VEGA, Inca, 1943 [1609] - Comentarios Reales de los Incas; Buenos Aires: Emecé Editorial.

GROSSMAN, J., 1972 - An ancient gold worker's tool kit. Archaeology, 25: 270-275.

HELMS, M., 1993 - Craft and kingly ideal, 272 p.; Austin: University of Texas Press.

HOSLER, D. \& STRESSER PAEN, 1992 - The Huastec Region, a second locus for the production of bronze alloys in Ancient Mesoamerica. Science, vol 257: 1215-1220.

INOMATA, T., 2001 - The power and Ideology of Artistic Creation. Elite Craft Specialists in Classic Maya Society. Current Anthropology, Volume 42, Number 3: 321-349; Chicago: University of Chicago-The Wenner-Gren Foundation for Anthropological Research.

JARA, G., 2000 - Producción de vasijas domésticas en un taller alfarero Moche: en la falda Noreste de Cerro Blanco-Valle de Moche. Trujillo: Escuela de Arqueología, Facultad de Ciencias Sociales, Universidad Nacional de Trujillo. Proyecto de investigación para optar el título de Licenciado en Arqueología.

KROEBER, A., 1925 - The Uhle Pottery Collections from Moche. University of California Publications in American Archaeology and Ethnology, 21 (5): 191-234; Berkeley.

LARCO H., R., 1948 - Cronología Arqueológica del Norte del Perú, 89 p.; Buenos Aires: Sociedad Geográfica Americana. 
LARCO H., R., 2001 - Los Mochicas. Tomos I y II, xxix + 333 + 350 p.; Lima: Museo Arqueológico Rafael Larco Herrera-Telefónica del Perú S. A.

LECHTMAN, H., ERLIJ, A. \& BARRY, E., 1982 - New perspectives on Moche Metallurgy: Techniques of Gilding Copper at Loma Negra, Northern Peru. American Antiquity, Volume 47, Issue 1: 3-30; Society for American Archaeology.

LEVIN, D., 1994 - L'or des dieux, I'or des Andes, 132 p.; Metz-Arsenal. Moselle: ediciones Serpenoise. Catálogo de la exposición organizada por le Conseil General de la Mosella.

MAKOWSKI, K., DONNAN, C., AMARO, I., CASTILLO, L. J., DIEZ CANSECO, M., ELÉSPURU, O. \& MURRO, J. A. 1994 - Vicús, xxiv +381 p.; Lima: Banco de Crédito del Perú. Colección Arte y Tesoros del Perú.

MORALES, R., 2003 - Iconografía litúrgica y contexto arquitectónico en Huaca de la Luna, valle de Moche. In: Moche: hacia el final del milenio (S. Uceda \& E. Mujica, eds.): 425476, T. I; Lima: Universidad Nacional de Trujillo y Pontificia Universidad Católica del Perú. Actas del Segundo Coloquio sobre la Cultura Moche (Trujillo, 1 al 7 de agosto de 1999).

MORALES, R., 2004 - Atuendo ritual Moche en Huaca de la Luna: aportes para una interpretación iconográfica en contexto. In: Investigaciones en la Huaca de la Luna 1998-1999 (S. Uceda, E. Mujica \& R. Morales, eds.): 377-387; Trujillo: Facultad de Ciencias Sociales de la Universidad Nacional de Trujillo.

PATTERSON, C., 1971 - Native Cooper, Silver, and Gold Accesible to Early Metallurgist. American Antiquity, Volume 36, Issue 3: 286-321: Society for American Archaeology.

RAMíREZ, S., 2002 - El mundo al revés. Contactos y conflictos transculturales en el Perú del siglo XVI, 349 p.: Lima: Fondo editorial de la Pontificia Universidad Católica del Perú.

RAVINES, R. (ed.), 1978 - Tecnología Andina, 821 p.; Lima: Instituto de Estudios PeruanosInstituto de Investigación Tecnológica Industrial y de Normas Técnicas.

RAVINES, R., 1994 - Minería y Metalurgia. In: Los Incas: Historia y Arqueología del Tahuantinsuyu (F. Silva Santisteban \& R. Ravines, eds); Lima: Editorial Brasa S.A. Serie Historia General del Perú. Tomo III.

REDMAN, C. L., 1990 - Los orígenes de la civilización. Desde los primeros agricultores hasta la sociedad urbana en el Próximo Oriente, 443 p.; Barcelona: Editorial Crítica/ Arqueología.

RENGIFO CHUNGA, C. E., 2005 - Talleres orfebres Mochicas en el Complejo Arqueológico Huacas de Moche: Secuencia y Estructura Espacial. Proyecto de Investigación para optar por el título de Licenciado en Arqueología. Universidad Nacional de Trujillo, Facultad de Ciencias Sociales, Escuela de Arqueología.

RENGIFO, C. \& ROJAS, C., 2005 - Especialistas y centros de producción en el complejo arqueológico Huacas de Moche: evidencias de un taller orfebre. In: Proyecto Arqueológico Huaca de la Luna. Informe Técnico 2004 (S. Uceda \& R. Morales, eds.): 377-390; Trujillo: Facultad de Ciencias Sociales de la Universidad Nacional de Trujillo.

RENGIFO, C. \& ROJAS, C., ms. - Talleres especializados en el Complejo Arqueológico Huacas de Moche: el carácter de los especialistas y de su producción. In: Avances en la Arqueología Mochica. Actas de la Primera Conferencia Internacional de Jóvenes Investigadores sobre la Cultura Mochica (L. J. Castillo, J. Rucabado, H. Bernier \& G. Lockard, eds.); Lima: Pontificia Universidad Católica del Perú (4 y 5 de agosto del 2004).

ROSTWOROWSKI, M., 2004 - Costa Peruana Prehispánica, 376 p.; Lima: Instituto de Estudios Peruanos (IEP). Obras Completas de María Rostworowski, Volumen III.

SHIMADA, I., 1994 - Pampa Grande and the Mochica Culture, 323 p.; Austin: University of Texas Press.

SHIMADA, I., 1994 - Late Moche Urban Craft Production: A First Aproximation. In: Moche Art and Archaeology in Ancient Peru (J. Pillsbury ed.): 177-205; Washington, D.C.: Center for Advanced Study in the Visual Arts, National Galery of Art. Symposium Papers XL, Studies in the History of Art 63. 
SHIMADA, I., 2001 - Late Moche urban craft production: a first approximation. In: Moche Art and Archaeology in Ancient Peru (J. Pillsbury, ed.): 177-205; Washington, D.C.: National Galery of Art. Studies in the History of Art 63. Center for Advanced Studies in the Visual Arts, Symposium Papers XL.

SHIMADA, I., EPSTEIN, S. \& CRAIG, A., 1982 - Batán Grande: A prehistoric Metallurgical Center in Peru. Science, Vol 216, 28: 952-959; American Asociation for Advancement Science (AAAS).

TEllO, R., AGRedA, G., CHIGUAlA, J., PINILLOS, G., TUFINIO, J. \& VELÁSQUEZ, O., 2000 - Investigaciones en el Conjunto Arquitectónico 30-Centro Urbano Moche. In: Investigaciones en la Huaca de la Luna 1999 (S. Uceda \& R. Morales, eds.): 167-221; Trujillo: Facultad de Ciencias Sociales de la Universidad Nacional de Trujillo.

TELLO, R., ARMAS, J. \& CHAPDELAINE, C., 2003 - Prácticas Funerarias Moche en el Complejo Arqueológico Huacas del Sol y de la Luna. In: Moche: hacia el final del milenio (S. Uceda \& E. Mujica, eds.): 151-187, T. I ; Lima: Universidad Nacional de Trujillo y Pontificia Universidad Católica del Perú. Actas del Segundo Coloquio sobre la Cultura Moche (Trujillo, 1 al 7 de agosto de 1999)..

TELLO, R., AGREDA, G., CHIGUALA, J., PINILLOS, G., TUFINIO, J. \& VELÁSQUEZ, O., 2004a Investigaciones iniciales en el conjunto arquitectónico 30, Área Urbana Moche. In: Investigaciones en la Huaca de la Luna 1998-1999 (S. Uceda, E. Mujica \& R. Morales, eds.): 261-312; Trujillo: Facultad de Ciencias Sociales de la Universidad Nacional de Trujillo.

TELLO, R., JORDÁN, C., ZEVALLOS, C., NúÑEZ, M., PONCE, A., CHIROQUE, M., MADUEÑO, C. \& MONGE, V., 2004b - Investigaciones en el conjunto arquitectónico 25, Área Urbana Moche. In: Investigaciones en la Huaca de la Luna 1998-1999 (S. Uceda, E. Mujica \& R. Morales, eds.): 231-260; Trujillo: Facultad de Ciencias Sociales de la Universidad Nacional de Trujillo.

TOPIC, J., 1990 - Craft production in the Kingdom of Chimor. In: The northern dynasties: kingship and statecraft in Chimor (M. Moseley \& A. Cordy-Collins, eds.): 145-176; Washington, D.C.: Dumbarton Oaks Research Library and Collection.

TOPIC, T., 1977 - Excavations at Moche. Tesis de doctorado; Cambrigde: Departament of Anthropology, Harvard University.

UCEDA, S., 2004 - Los sacerdotes del arco bicéfalo: tumbas y ajuares hallados en Huaca de la Luna y su relación con los rituales Moche. In: Proyecto Arqueológico Huaca de la Luna. Informe técnico 2003 (S. Uceda \& R. Morales, eds.): 237-259; Trujillo: Facultad de Ciencias Sociales, Universidad Nacional la Libertad.

UCEDA, S., ms. - Los de Arriba y los de Abajo: Relaciones sociales, políticas y económicas entre el templo y los habitantes en el centro urbano de las Huacas de Moche. In: Nuevas Perspectivas en la Organización Politica Mochica (L. J. Castillo \& J. Quilter, eds.); Lima: Pontificia Universidad Católica del Perú, Dumbarton Oaks y Museo Arqueológico Rafael Larco Herrera. Actas del Congreso «Nuevas Perspectivas en la Organización Política Mochica» (Lima, 6 al 8 de agosto del 2004).

UCEDA, S. \& ARMAS, J., 1997 - Los talleres alfareros en el Centro Urbano Moche. In: Investigaciones en la Huaca de la Luna 1995 (S. Uceda, E. Mujica \& R. Morales, eds.): 93-104; Trujillo: Facultad de Ciencias Sociales, Universidad Nacional de Trujillo.

UCEDA, S. \& ARMAS, J., 1998 - An urban pottery workshop at the site of Moche, North Coast of Peru. In: MASCA Research Papers in Science and Archaeology, supplement to Vol 15: 91-110; Philadelphia: University of Pennsylvania Museum of Archaeology and Anthropology.

UCEDA, S., MUJICA, E. \& MORALES, R. (eds.), 1997 - Investigaciones en la Huaca de la Luna 1995, 239 p.; Trujillo: Facultad de Ciencias Sociales de la Universidad Nacional de La Libertad - Trujillo. 
UCEDA, S., MUJICA, E. \& MORALES, R. (eds.), 1998 - Investigaciones en la Huaca de la Luna 1996, 251 p.; Trujillo: Facultad de Ciencias Sociales de la Universidad Nacional de La Libertad - Trujillo.

UCEDA, S., MUJICA, E. \& MORALES, R. (eds.), 2000 - Investigaciones en la Huaca de la Luna 1997, 330 p.; Trujillo: Facultad de Ciencias Sociales de la Universidad Nacional de Trujillo.

UCEDA, S., MUJICA, E. \& MORALES, R. (eds.), 2004 - Investigaciones en la Huaca de la Luna 1998-1999, 495 p.; Trujillo: Facultad de Ciencias Sociales de la Universidad Nacional de Trujillo.

UCEDA, S. \& TUFINIO, M., 2003 - El complejo arquitectónico religioso Moche Huaca de la Luna: una aproximación a su dinámica ocupacional. In: Moche: hacia el final del milenio (S. Uceda \& E. Mujica, eds.): T. II: 179-288; Lima: Universidad Nacional de Trujillo y Pontificia Universidad Católica del Perú. Actas del Segundo Coloquio sobre la Cultura Moche (Trujillo, 1 al 7 de agosto de 1999). 